\title{
La participación de la moneda en la ceremonia de enterramiento tardopúnica de Gadir*
}

\author{
The use of coins in the late Punic burial ceremony of Gadir
}

Alicia Arévalo González ${ }^{a}$ y Elena Moreno Pulido ${ }^{a}$

\section{RESUMEN}

El objetivo del presente trabajo es analizar la incidencia y funcionalidad de las deposiciones monetales en las tumbas de la necrópolis tardopúnica de Gadir. Para ello, se ha llevado a cabo una sistemática extracción de la información contenida en las memorias de las intervenciones arqueológicas urbanas depositadas en la Delegación de Cultura de Cádiz. El examen detenido de estos datos, muchos inéditos, nos ha permitido acercarnos a la participación del numerario en los diferentes actos que componían los ceremoniales de enterramiento, tanto en inhumaciones como en cremaciones, como testimonio de un variado elenco de momentos rituales en los que la moneda tuvo un papel peculiar. Si bien son escasos, los testimonios abordados muestran de qué forma el numerario se incorporó de manera multifacética a las creencias y escatologías del tradicional ceremonial funerario fenicio en Gadir.

\begin{abstract}
The main purpose of this paper is to analyse the incidence and functionality of the monetary depositions located in the graves of the late Punic necropolis of Gadir. We have carried out a systematic extraction of the information found in the reports of the mainly unpublished archaeological excavations in Cadiz. The detailed study of this data permits us to assess how the money was used in
\end{abstract}

the various actions that constituted the funerary ceremony (both inhumations and cremations), so as to reconstruct the range of ritual moments when coins were required. The evidence is sparse, but it shows how coinage was assimilated in multiple ways to the beliefs and the liturgy of the traditional Phoenician funerary ritual in Gadir.

Palabras clave: Arqueología de la muerte; Numismática Antigua; Cádiz; Siglos III-I a.C.; Ceremonial fúnebre.

Key words: Mortuary archaeology; Ancient numismatics; Cadiz; 3rd to 1st centuries B.C.; Funeral ceremonies.

\section{RECONSTRUYENDO EL PAPEL DE LA MONEDA EN EL RITUAL FUNERARIO TARDOPÚNICO GADIRITA: ALGUNOS APUNTES METODOLÓGICOS}

La moneda en el mundo funerario gadirita ha sido objeto de un detenido análisis financiado por el Proyecto de Investigación I+D+i HAR201016793, cuyas conclusiones se han comenzado a presentar en diferentes foros. Se buscaba entonces dar a conocer la incidencia y los usos del numerario hallado en las necrópolis de Gadir, Malaka y Ebusus desde su primera aparición en estos ambientes, a finales del periodo púnico, hasta el cese

\footnotetext{
* Proyecto de Investigación I+D+i "Moneda para el Más Allá. Estudio diacrónico del uso y significado de la moneda en las necrópolis de Gadir, Malaka y Ebusus" (HAR2010-16793), Ministerio de Economía y Competitividad del Gobierno de España.

a Universidad de Cádiz. Avenida Dr. Gómez Ulla 1. 11001 Cádiz. Correos e.: Alicia.arevalo@uca.es http://orcid.org/0000-00018114-3385; Elena.moreno@uca.es http://orcid.org/0000-0003-0330-4491.

Recibido 12-I-2016; aceptado 3-III-2016.
}

Copyright: (C) 2017 CSIC. Este es un artículo de acceso abierto distribuido bajo los términos de una licencia de uso y distribución Creative Commons Attribution (CC-by) España 3.0. 
de la Antigüedad. No obstante, en este trabajo profundizaremos exclusivamente en los resultados obtenidos sobre la participación de la moneda en la ritualidad funeraria gadirita de enterramiento durante los siglos III al I a.C. (Fig. 1). La fase cultural tardopúnica ha sido escasamente tratada en la bibliografía $y$, pese a su especial naturaleza, su caracterización a menudo se ha diluido en el análisis del período romano republicano. Sin embargo, es un interesantísimo momento de transición donde tradición e integración se dan de la mano. La cultura fenicio-púnica impregna todavía todos los aspectos de la vida cotidiana de los ciudadanos de Gadir (Ferrer Albelda 2006, 2010; Vaquerizo Gil, 2010a, 2010b; Arévalo González 2012; Arévalo González y Moreno Pulido 2011, Sáez; Luaces y Moreno 2016, entre otros trabajos), que van transformándose, aunque no perdiéndose por completo, gracias, precisamente, a la interacción con Roma. Esta etapa encontró en el mundo funerario formas de expresión que, si bien mantienen el sentido tradicional del rito fúnebre, hacen gala del uso de nuevas formas, como la moneda.

Recordemos que el numerario en Gadir no parece acuñarse con seguridad hasta inicios del siglo III a.C. (Alfaro 1988), en un momento tardío en general respecto al Mediterráneo central y oriental y tras la acuñación de moneda en otros focos hispanos como Emporion (Ampurias, Gerona), Rhode (Roses, Gerona), Ebusus (Ibiza), Arse (Sagunto, Valencia) o Saitabi (Játiva, Valencia), quienes se inician en la economía monetaria entre V y IV a.C. Sólo a finales del periodo púnico Gadir comienza a emitir moneda. Escogerá para sus anversos la imagen del dios tutelar de la ciudad, Melqart-Heracles, en su forma helenística y alejandrina, que mantendrá durante toda su acuñación, acompañándose en reverso de atunes o delfines, si bien, los motivos variarán en función de los distintos valores (Fig. 2). Alfaro (1988) sistematizaría el monetario gadirita en siete series, acuñadas en bronce, excepto la segunda, argéntea (Fig. 2C). Las cinco primeras emisiones corresponderían aún al final del periodo plenamente púnico y se fecharían correlativamente en el siglo III a.C. La sexta serie, acuñada ya bajo dominio romano con valores y funcionalidad plenamente económicas, sería el exponente más representativo de la etapa tardopúnica (Fig. 2D). La serie monetaria séptima, última emisión vinculada expresamente con Augusto y la familia imperial, marca de una forma muy clara el paso cultural, económico y político de la fenicia Gadir a la romana Gades. Por ello, en este trabajo no incluiremos los hallazgos monetarios de esta serie en ambiente funerario.

La mayoría de los hallazgos monetarios de la ciudad corresponden a la sexta serie de Gadir (Alfaro 1988; Arévalo y Moreno 2011), cuestión extensible a los numismas recuperados exclusivamente en ámbito funerario, que son los que nos interesan ahora. En ese ámbito hemos recopilado un total de 110 piezas de esta serie, de las que presentamos las 66 procedentes de tumbas fechadas en la etapa que nos concierne ${ }^{1}$.

La indefinición cronológica de la sexta serie de Gadir (Fig. 2D) se amplía a la mayoría de los enterramientos exhumados en las distintas necrópolis de la ciudad. Los ajuares, muy a menudo, o son excesivamente pobres o carecen de elementos que permitan ofrecer una datación ajustada. Ello dificulta en gran medida un esclarecimiento más detallado de la cronología de cada sepelio, amén del mal estado general del registro, pues en buena parte de los informes administrativos pocos aportes cronológicos van más allá de una genérica adscripción de las tumbas a la época republicana o bien a los siglos III-I a.C. Debemos reconocer las limitaciones del uso de la moneda como criterio cronológico post quem ya que, unido a la longevidad de la sexta emisión de Gadir, por razones de prestigio, fue común escoger la pieza más antigua disponible para las deposiciones funerarias. Esta cuestión se desprende del usual desgaste con el que nos encontramos estos numismas, ya que los casos en los que la antigua moneda de Gadir aparece en enterramientos de los siglos I y II d.C. junto a moneda imperial romana (Arévalo González 2012) constatan de forma clara cómo no siempre los sepelios y las monedas depositadas en los mismos son coetáneos.

Para este trabajo hemos revisado los contextos y los ajuares a partir de la información contenida en las memorias de las intervenciones de cada una de las tumbas estudiadas. Presentamos únicamen-

\footnotetext{
${ }^{1}$ Las cinco primeras emisiones de la ciudad, recuperadas en toda la necrópolis gadirita, forman un conjunto de 29 monedas. De las 17 vinculadas expresamente a sepulturas 8 corresponden a la serie I y se hallaron en sendas tumbas, 1 a la serie II, 1 a la serie III, 5 a la serie IV y 2 a la serie V.
} 


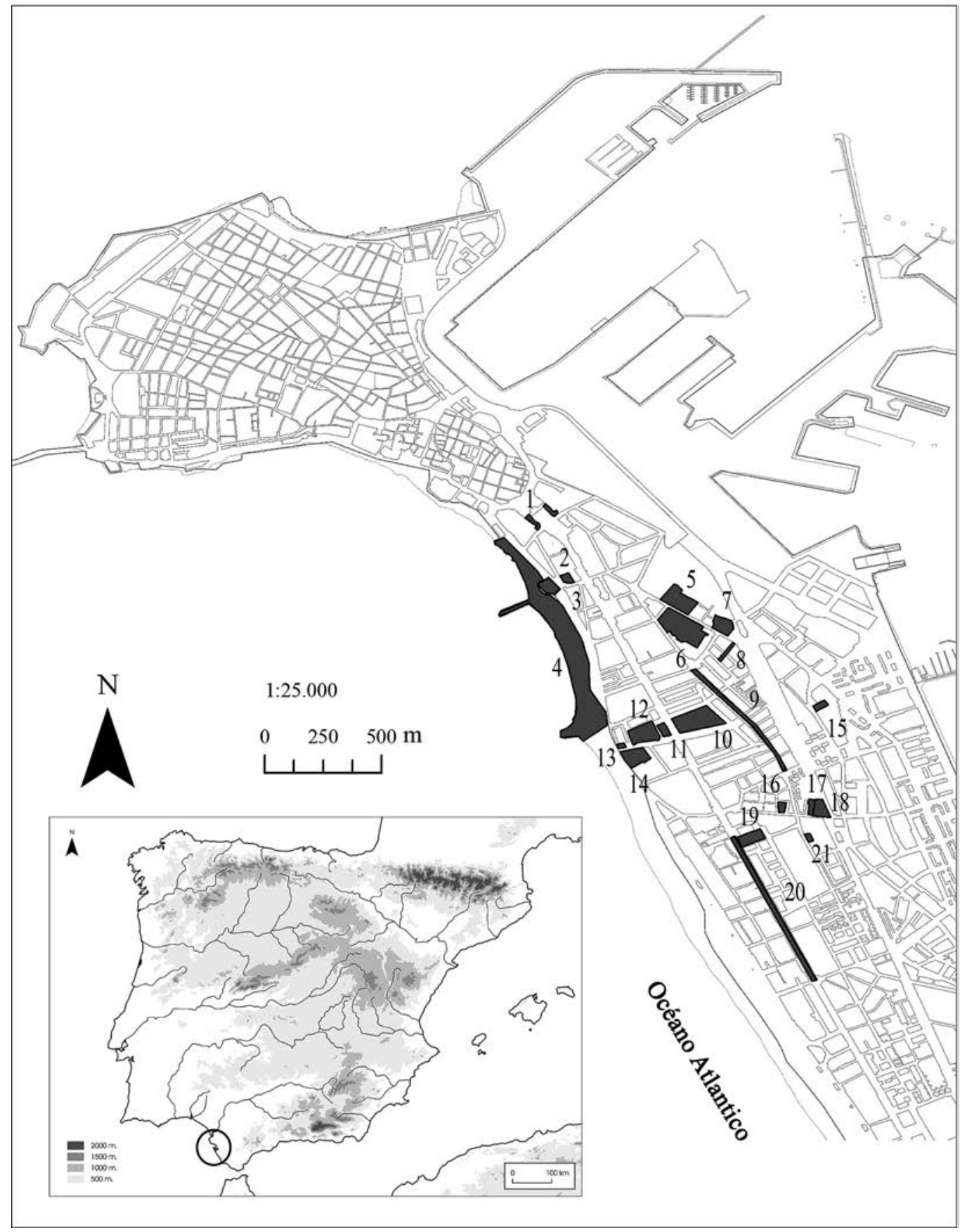

Fig. 1. Localización de la ciudad de Cádiz en la península ibérica y plano de la ciudad con la ubicación de las intervenciones arqueológicas con hallazgos monetarios en tumbas fechadas entre los siglos III-I a. C.: 1. Glacis de Puerta Tierra; 2. C/ Santa Cruz de Tenerife $n^{\circ}$ 1, esquina c/ Santa María del Mar; 3. Baños del Blanco; 4. Playa de los Corrales; 5. C/Tolosa Latour $n^{\circ}$ 3; 6. Solar del pabellón Fernando Portillo; 7. Solar de la futura Ciudad de la Justicia; 8. C/ Bellavista; 9. C/ García de Sola, alcantarillado; 10. Solar de los Antiguos Cuarteles de Varela; 11. Av. Andalucía esquina Plz. de Asdrúbal; 12. Plz. de Asdrúbal; 13. Plz. de Asdrúbal esquina con Paseo Marítimo; 14. Av. Amilcar Barca s/n; 15. Av. San Severiano no 21; 16. C/ Campos Elíseos no 6 y 13; 17. Av. de Portugal esquina con Av. Juan Carlos I; 18. Soterramiento de la vía férrea a la altura de la Av. de Portugal; 19. Plz. de Jesús de la Paz y Av. Ana de Viya s/n 20; Av. Ana de Viya; 21. C/ García Carrera nº 9. (Plano de las autoras). 


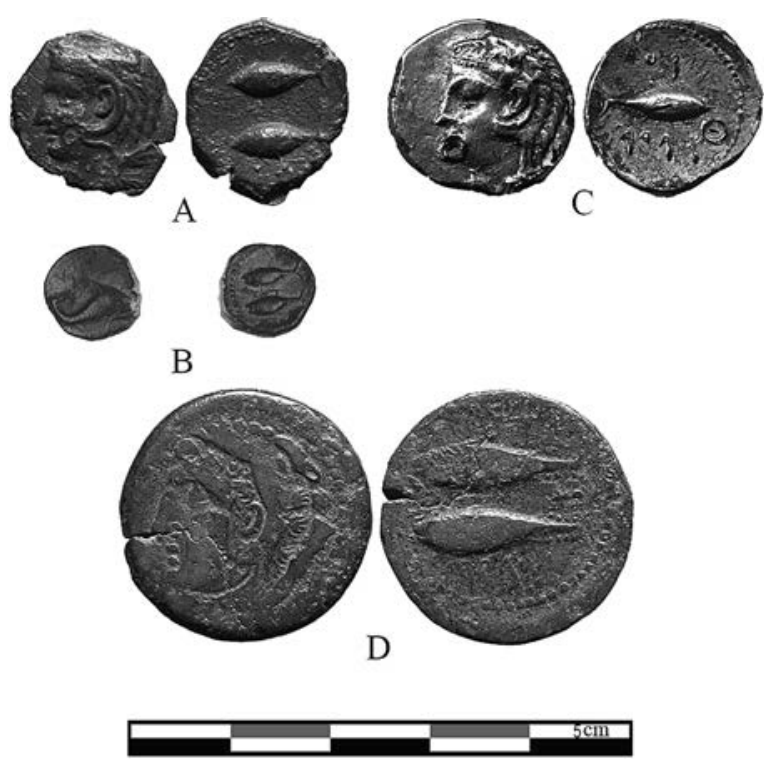

Fig. 2. Ejemplos de la primera (I), segunda (II) y sexta (VI) emisión monetaria de Gadir (Alfaro 1988): A. Mitad (Serie I.1) MAN1958/54/32; B. Octavo (Serie I.3.1). MAN1993/67/123; C. Hemishekel de la Serie II.A.1, Museo Provincial de Cádiz no 14518; D. Unidad de la Serie VI.B.1.1, MAN1993/67/393. A, B, D proceden de ceres.mcu (Fecha de consulta 27/12/2015); C fotografía de A. Arévalo.

te aquellas adscribibles sin dudas al periodo tardopúnico, si bien en algunos casos, por las razones expuestas, su datación no ha podido perfilarse más allá de esta amplia horquilla cronológica.

Partiremos de la base de que tampoco contamos actualmente con un estudio arqueológico detallado sobre las necrópolis de Gadir. Ramos Sainz (1990) abordó someramente este tema, manejando, lógicamente, muchos menos datos de campo de los que disponemos hoy en día. Además, esta autora apenas se detiene en los pormenores funerarios del periodo tardopúnico. Esta cuestión puede trasladarse de forma genérica a la bibliografía actual, donde se ha prestado mayor atención al periodo arcaico (Gras et al. 1989: 162 ss.), destacando los trabajos sobre la necrópolis fenicia gadirita de los siglos VI-IV a.C. de Perdigones, Muñoz y Pisano (1990) o Belén (1992-1993). Subrayamos también la reciente recopilación de nuevos estudios puntuales sobre las distintas fases de los cementerios de la ciudad (Niveau de Villedary y Gómez Fernández 2010).
Asimismo, el momento tardopúnico sufre la carestía de trabajos generales o específicos del mundo funerario en el resto del Mediterráneo, donde tradicionalmente han recibido mayor atención los periodos fenicio-arcaico y helenísticopúnico. Destacan para esos momentos, entre otras publicaciones, las de Aubet $(2006,2010)$ sobre las cremaciones tirias durante la Edad del Hierro, la recopilación, editada por González Prats (2005), derivada del seminario sobre el mundo funerario fenicio, las reconstrucciones de Ribichini (1987) sobre la religiosidad en el periodo de esplendor de Cartago o la obra de Benichou-Safar (1982) fundamental para los aspectos más materiales. Para la Península Ibérica recordaremos los trabajos de Jiménez Flores $(1996,2002)$ y de Prados Martínez (2008) y para la etapa romano-imperial, los de Vaquerizo (2010a, 2010b).

Queremos ir supliendo esta falta de estudios de síntesis sobre esta etapa tardopúnica de confrontación, perduración y asimilación política, económica y cultural con contribuciones como la presente. No obstante, hemos de relativizar las conclusiones que se derivan de la nuestra, pues están extraídas del análisis de las tumbas excavadas en la necrópolis de Gadir correspondientes a los siglos III-I a.C. que contuvieron moneda. Para dicho análisis hemos revisado todos los informes, publicados o inéditos, de las campañas de excavaciones realizadas en ámbito funerario gaditano donde se halló numerario. De las más de 2508 tumbas recopiladas correspondientes a la Antigüedad (IV a. C.-IV d.C.) sólo 288 contenían moneda $(11,48 \%$ del total analizado). De éstas, 29 tumbas (23 inhumaciones y 6 cremaciones) pertenecen al final del periodo púnico (Tab. 1, Fig. 1), apenas un $1 \%$ del total. Es obvio que la incidencia de este rito en las necrópolis de Gadir fue ínfima, aun así, pensamos que los casos en los que se recuperó moneda son muy sugestivos y su análisis en detalle ofrece la posibilidad de ahondar un poco más en nuestros precarios conocimientos de esta necrópolis y su ritualidad. Trataremos estos datos de forma cualitativa, teniendo en cuenta el escaso porcentaje de incidencia de la moneda en las tumbas gadiritas, que además es similar al ofrecido por los amuletos a los que, con el tiempo, las monedas parecieron sustituir. Es interesante añadir en este sentido que, de las 720 tumbas excavadas en Palermo, sólo un 15\% contenían amuletos y sólo un 3\% espejos (Ribichini 2005:

Trab. Prehist., 74, N. ${ }^{\circ}$ 1, enero-junio 2017, pp. 127-148, ISSN: 0082-5638

doi: $10.3989 /$ tp.2017.12187 


\begin{tabular}{|c|c|c|c|c|c|c|c|c|c|}
\hline \multirow{2}{*}{ Interv. } & \multirow{2}{*}{ Rito } & \multirow{2}{*}{$\begin{array}{l}\text { Tipología } \\
\text { tumba }\end{array}$} & \multirow{2}{*}{$\begin{array}{l}\text { Posición } \\
\text { cadáver }\end{array}$} & \multirow{2}{*}{$\begin{array}{l}\text { Sexo y/o } \\
\text { edad }\end{array}$} & \multirow{2}{*}{ Ajuar } & \multicolumn{3}{|c|}{ Moneda } & \multirow{2}{*}{$\begin{array}{c}\text { Cronología } \\
\text { tumba }\end{array}$} \\
\hline & & & & & & Ubicación & Asociado & $\mathbf{N}^{\circ}$ & \\
\hline 1 & $\mathrm{C}$ & Secundarias & - & - & - & Urnas & - & 5 & - \\
\hline 2 & I & Fosa cubierta & $\begin{array}{l}\text { Decúbito } \\
\text { supino }\end{array}$ & Adulto & $\begin{array}{l}\text { Sello en la } \\
\text { mano. Clavo en } \\
\text { el cráneo }\end{array}$ & Depósito & No & 1 & II-I a.C.? \\
\hline 3.1 & I & $\begin{array}{l}\text { Fosas } \\
\text { descubiertas }\end{array}$ & - & - & - & - & - & 2 & - \\
\hline 3.2 & $\mathrm{C}$ & Secundarias & - & - & - & Urnas & - & 13 & - \\
\hline 4 & $\mathrm{C}$ & Secundarias & - & - & - & Urnas & - & +1 & III-I a.C.? \\
\hline 5.1 & I & $\begin{array}{l}\text { Fosa } \\
\text { descubierta }\end{array}$ & $\begin{array}{l}\text { Decúbito } \\
\text { supino }\end{array}$ & Adulto & $\begin{array}{l}\text { Ungüentarios en } \\
\text { el cuello }\end{array}$ & Pies & $\begin{array}{l}\text { Vasos, olla, } \\
\text { cuenta, aguja }\end{array}$ & 1 & III-II a.C.? \\
\hline 5.2 & I & $\begin{array}{l}\text { Fosa } \\
\text { descubierta }\end{array}$ & $\begin{array}{l}\text { Decúbito } \\
\text { supino }\end{array}$ & Adulto & $\begin{array}{l}\text { Ungüentarios, } \\
\text { ollita, cuenco, } \\
\text { vaso y espejo, en } \\
\text { tibias }\end{array}$ & Mano & No & 1 & III-II a.C.? \\
\hline 6 & I & $\begin{array}{l}\text { Fosa } \\
\text { descubierta }\end{array}$ & $\begin{array}{l}\text { Decúbito } \\
\text { supino }\end{array}$ & - & $\begin{array}{l}\text { Anillo, cuenta, } \\
\text { ungüentarios en } \\
\text { torno y en tibias }\end{array}$ & Mano & No & 1 & II-I a.C. \\
\hline 7.1 & $\mathrm{C}$ & Secundaria & - & - & No & & No & 2 & III-I a.C.? \\
\hline 7.2 & I & $\begin{array}{l}\text { Fosa } \\
\text { descubierta }\end{array}$ & $\begin{array}{l}\text { Decúbito } \\
\text { supino }\end{array}$ & $\begin{array}{l}\text { Femenino } \\
\text { Adulto }\end{array}$ & No & Pies & Cuentas & 1 & III-I a.C.? \\
\hline 7.3 & I & Fosa cubierta & $\begin{array}{l}\text { Decúbito } \\
\text { supino }\end{array}$ & $\begin{array}{l}\text { Femenino } \\
\text { Adulto }\end{array}$ & $\begin{array}{l}\text { Arete en cráneo, } \\
\text { anillo en la mano }\end{array}$ & - & No & 1 & III-I a.C.? \\
\hline 7.4 & I & Fosa cubierta & $\begin{array}{l}\text { Decúbito } \\
\text { supino }\end{array}$ & \begin{tabular}{|l} 
Femenino \\
Joven
\end{tabular} & $\begin{array}{l}\text { Anillo en la } \\
\text { mano }\end{array}$ & Tórax & No & 1 & III-I a.C.? \\
\hline 7.5 & I & Cista & $\begin{array}{l}\text { Decúbito } \\
\text { supino }\end{array}$ & \begin{tabular}{|l|} 
Masculino \\
Adulto \\
\end{tabular} & $\begin{array}{l}\text { Ungüentarios y } \\
\text { golletes }\end{array}$ & Relleno & No & 1 & III-I a.C.? \\
\hline 8 & I & \begin{tabular}{|l}
$\begin{array}{l}\text { Fosa } \\
\text { descubierta }\end{array}$ \\
\end{tabular} & - & - & - & - & - & 1 & - \\
\hline 9 & I & \begin{tabular}{|l}
$\begin{array}{l}\text { Fosa } \\
\text { descubierta }\end{array}$ \\
\end{tabular} & - & Adulto & No & - & No & 1 & II-I a.C. \\
\hline 10.1 & $\mathrm{C}$ & Secundaria & - & - & $\begin{array}{l}\text { Ungüentario, } \\
\text { clavos, placas de } \\
\text { plomo y fauna }\end{array}$ & & No & 2 & I a.C. \\
\hline 10.2 & $\mathrm{C}$ & Secundaria & - & - & $\begin{array}{l}\text { Epígrafes, } \\
\text { cerámica, } \\
\text { ungüentarios, } \\
\text { lucerna y fauna }\end{array}$ & - & - & 2 & I a.C. \\
\hline 10.3 & I & Fosa cubierta & $\begin{array}{l}\text { Decúbito } \\
\text { supino }\end{array}$ & Masculino & Ungüentario & - & No & 1 & II a.C. \\
\hline 11 & I & \begin{tabular}{|l|}
$\begin{array}{l}\text { Fosas } \\
\text { cubiertas }\end{array}$ \\
\end{tabular} & - & - & - & Fosa & No & 1 & - \\
\hline 12 & - & - & - & - & - & $\begin{array}{l}- \\
3 \text { junto a la } \\
\text { tumba }\end{array}$ & - & 14 & - \\
\hline 13 & I & $\begin{array}{l}\text { Fosa } \\
\text { descubierta }\end{array}$ & $\begin{array}{l}\text { Decúbito } \\
\text { supino }\end{array}$ & Adulto & $\begin{array}{l}\text { Ungüentario } \\
\text { junto a la cadera }\end{array}$ & Tórax & Cuentas & 1 & III-I a.C. \\
\hline 14 & I & Fosa cubierta & $\begin{array}{l}\text { Decúbito } \\
\text { prono }\end{array}$ & - & $\begin{array}{l}\text { Anillo en la } \\
\text { mano }\end{array}$ & Cabeza & No & 1 & - \\
\hline
\end{tabular}




\begin{tabular}{|c|c|c|c|c|c|c|c|c|c|}
\hline \multirow{2}{*}{ Interv. } & \multirow{2}{*}{ Rito } & \multirow{2}{*}{$\begin{array}{c}\text { Tipología } \\
\text { tumba }\end{array}$} & \multirow{2}{*}{$\begin{array}{l}\text { Posición } \\
\text { cadáver }\end{array}$} & \multirow{2}{*}{$\begin{array}{l}\text { Sexo y/o } \\
\text { edad }\end{array}$} & \multirow{2}{*}{ Ajuar } & \multicolumn{3}{|c|}{ Moneda } & \multirow{2}{*}{$\begin{array}{c}\text { Cronología } \\
\text { tumba }\end{array}$} \\
\hline & & & & & & Ubicación & Asociado & $\mathbf{N}^{\mathbf{0}}$ & \\
\hline 15 & I & $\begin{array}{l}\text { Fosa } \\
\text { descubierta }\end{array}$ & $\begin{array}{l}\text { Decúbito } \\
\text { supino }\end{array}$ & - & $\begin{array}{l}\text { Ungüentarios en } \\
\text { el brazo }\end{array}$ & Fosa & No & 1 & I a.C. \\
\hline 16 & I & $\begin{array}{l}\text { Fosa } \\
\text { descubierta }\end{array}$ & - & - & Ungüentarios & - & No & 2 & II a.C.? \\
\hline 17 & I & $\begin{array}{l}\text { Fosa } \\
\text { descubierta }\end{array}$ & $\begin{array}{l}\text { Decúbito } \\
\text { supino }\end{array}$ & - & $\begin{array}{l}\text { Ungüentarios en } \\
\text { cuello, brazo y } \\
\text { cabeza }\end{array}$ & Brazo & No & 3 & II-I a.C.? \\
\hline 18 & I & Fosa cubierta & $\begin{array}{l}\text { Decúbito } \\
\text { supino }\end{array}$ & Adulto & Anillo & Sobre Tumba & No & 1 & III-II a.C. \\
\hline 19 & I & $\begin{array}{l}\text { Fosa } \\
\text { descubierta }\end{array}$ & $\begin{array}{l}\text { Decúbito } \\
\text { supino }\end{array}$ & - & No & Pies & $\begin{array}{l}\text { Ungüentario } \\
\text { y clavo }\end{array}$ & 1 & - \\
\hline 20 & I & Cista & - & - & - & - & - & 1 & - \\
\hline 21 & $\mathrm{C}$ & Secundaria & & $\begin{array}{l}\text { Femenino } \\
\text { Joven? }\end{array}$ & $\begin{array}{l}\text { Caja, arete, disco, } \\
\text { píxide, espejo, } \\
\text { agujas, cartucho, } \\
\text { cucharillas, } \\
\text { ungüentario, } \\
\text { astrágalos }\end{array}$ & Caja & - & 38 & I a.C. \\
\hline
\end{tabular}

Tab. 1. Intervenciones arqueológicas (Interv.) de la necrópolis de Gadir (localización en Fig. 1) con hallazgos monetarios en tumbas con ritos de cremación (C) e inhumación (I): 1. Glacis de Puerta Tierra; 2. C/ Santa Cruz de Tenerife $n^{\circ} 1$, esquina c/ Santa María del Mar; 3. Baños del Blanco; 4. Playa de los Corrales; 5. C/ Tolosa Latour n 3; 6. Solar del pabellón Fernando Portillo; 7. Solar de la futura Ciudad de la Justicia; 8. C/ Bellavista; 9. C/ García de Sola, alcantarillado; 10. Solar de los Antiguos Cuarteles de Varela; 11. Av. Andalucía esquina Plz. de Asdrúbal; 12. Plz. de Asdrúbal; 13. Plz. de Asdrúbal esquina con Paseo Marítimo; 14. Av. Amilcar Barca s/n; 15. Av. San Severiano n 21; 16. C/ Campos Elíseos $\mathrm{n}^{\circ} 6$ y 13; 17. Av. de Portugal esquina con Av. Juan Carlos I; 18. Soterramiento de la vía férrea a la altura de la Av. de Portugal; 19. Plz. de Jesús de la Paz y Av. Ana de Viya s/n 20; Av. Ana de Viya; 21. C/ García Carrera nº 9.

272), lo que sugiere que el uso excepcional de determinados objetos de ajuar no se restringió en la Antigüedad a la moneda.

Por otra parte, hemos tratado de analizar si existió alguna correlación entre los datos antropológicos y numismáticos proporcionados en cada intervención arqueológica (Tab. 1). Desafortunadamente, solemos desconocer la posición exacta en la tumba del cuerpo del difunto, cuyo sexo o edad se han perdido irremisiblemente. Los estudios paleontológicos escasean, por lo que únicamente sabemos, con dudas, que de las 23 inhumaciones presentadas, 3 pudieron haber correspondido a mujeres y 3 a hombres, quedando 18 cadáveres sin confirmar. En consecuencia, podemos intuir, pero no afirmar de modo concluyente, que el rito pareció darse por igual en hombres y mujeres.

La determinación de la edad de los fallecidos enterrados con moneda enfrenta el mismo problema. Únicamente podemos afirmar de forma genérica que 9 eran adultos y 2, posiblemente, jóvenes, si bien uno estaba cremado y su edad y sexo se infirieron por la inclusión de un pendiente de oro y un juego de tabas entre el ajuar. La ausencia de moneda en los cadáveres infantiles en la necrópolis de Gadir no se observa en los enterramientos infantiles de otros cementerios datados entre los siglos IV y III a.C., como los de Puig des Molins (Ibiza) (Fernández 1992: 52; Gómez Bellard y Gómez Bellard 1989).

En la búsqueda de una caracterización detallada del ritual gadirita hemos atendido también a la posición del cuerpo inhumado. Tenemos datos de la posición de 15 de los 23 cadáveres referidos, sepultados con moneda. Se colocaron cuidadosamente en posición decúbito supino, salvo uno que se colocó en decúbito prono. No sorprende este hecho, dado que la colocación en decúbito supino pareció ser la forma habitual de tratar a los fallecidos entre la población sedentaria, siendo el decúbito dorsal al parecer más propio de la población beréber, como se ha demostrado significativamente en Cartago (Benichou-Safar 1982: 258). 
La excepción gadirita corresponde a la tumba 17 de la Avenida Amílcar Barca. Según describen sus excavadores ${ }^{2}$, el cuerpo fue arrojado sin cuidado, directamente sobre la fosa en decúbito prono, es decir, con el rostro sobre la tierra. Junto a su cabeza se depositó, curiosamente, una moneda y en sus manos llevaba un anillo de oro. Vaquerizo (2011), en su estudio de las necrópolis romanas béticas, propone que el difunto estuviera aquejado de una terrible enfermedad que provocara rechazo o miedo entre la sociedad entre las causas que llevarían a tratar al fallecido de esta forma, al parecer, poco ortodoxa e irrespetuosa. Un posible origen étnico del cadáver (quizás norteño o celta) podría explicar esta situación, aunque ello no aclararía el mínimo porcentaje de cuerpos aparecidos. Si esta posición derivase de una identidad étnica, seguramente sería imitada por unidades familiares amplias, en cuyo caso encontraríamos más difuntos boca abajo. Una vez más, la carencia actual de estudios antropológicos y de ADN nos impiden resolver esta disyuntiva.

Otra hipótesis contempla la muerte violenta de los individuos enterrados en decúbito prono. Pero el asesinato y el hurto no podrían explicar ni el extraño posicionamiento del difunto al que nos referimos, pues fue enterrado con un anillo de oro bajo las manos, ni tampoco la deposición intencionada, litúrgica, junto a su cabeza, de un octavo de la serie I.3 de Gadir (Fig. 2B). Habría que considerar otras posibilidades, como una ritualidad ancestral con raíz oriental y quizás inspirada en el recuerdo ugarítico (KTU 1.17: VI 26 ss) ${ }^{3}$.

Es obvio que la escasez de estudios antropológicos en la necrópolis, así como las exiguas descripciones de los enterramientos contenidas en los informes juegan en contra de que podamos reconstruir con mayor precisión la multiplicidad de situaciones de la compleja escatología fenicia. Resulta fundamental profundizar en los detalles de testimonios arqueológicos concretos, como los que actualmente presentamos, dado que los exiguos textos literarios sobre la liturgia fenicia que conservamos carecen de pasajes concretos sobre

\footnotetext{
2 Sibón, J. F. 2001: Memoria preliminar de los resultados obtenidos de la excavación realizada en la Avda. Amílcar Barca. Secretaría General de la Seguridad social de Cádiz (junio-julio de 2001). Memoria inédita depositada en la Delegación Provincial de Cultura de Cádiz: 18-19.

${ }^{3}$ Keilschrift Texte aus Ugarit.
}

las disposiciones luctuosas necesarias a la hora de llevar a cabo un enterramiento (Ribichini 1987: 147-161; Sader 2005: 80). En nuestro caso, la moneda nos servirá como hilo conductor, mediante su confrontación con las fuentes mitológicas y literarias orientales ${ }^{4}$ y la revisión de los contextos arqueológicos, para intentar comenzar a atisbar, aunque mínimamente, aspectos tan complejos como la ritualidad y la concepción de la vida y la muerte en las sociedades fenicio-púnicas de los siglos III a I a.C.

\section{EL RITO LUCTUOSO Y LAS FASES DE INCORPORACIÓN DE LA MONEDA EN LA TUMBA}

En la bibliografía actual contamos con múltiples tentativas de reconstrucción de las distintas ceremonias que componían los ritos de enterramiento fenicio, cartaginés y púnico. Como algunos trabajos representativos citamos los de Xella (1987a, 1987b), Jiménez Flores (1996), González Prats (2005), Bartoloni (2005, 2015), Prados (2008), Aubet $(2010,2013)$ o Elayi (2010). Pese a su interés, desgraciadamente ninguno ha tenido en cuenta e incorporado en el análisis el potencial papel especial de la moneda en cada uno de los sucesivos momentos que completaban los ceremoniales de inhumación y cremación.

En nuestra opinión, ello se debe no sólo a la escasa asiduidad de monedas en los sepulcros, sino también al exiguo tratamiento que suelen merecer en los informes y memorias de excavación. En la mayoría de las ocasiones, las monedas únicamente se citan sin tener en cuenta la estratigrafía o contexto en el que fueron recuperadas, con la consiguiente lógica e inevitable pérdida de información y de datos concretos para la interpretación. Sin embargo, algunas de las intervenciones que recuperaron numerario en las necrópolis de Gadir han conservado datos que apuntan a que la escatología tardopúnica gadirita fue mucho más compleja de

\footnotetext{
${ }^{4}$ La mitología mesopotámica y los textos bíblicos del Antiguo Testamento están generalmente aceptados como fuentes indispensables para la interpretación de la escatología y religiosidad fenicio-púnica, junto a los escritos redactados por Filón de Biblos y Eusebio de Cesarea, dada la carencia de este tipo de literatura en los textos propiamente vinculados a esta cultura (Ribichini 1986: 42; 1987; Garbini 1987; Jiménez Flores 1996: 70, etc.).
} 
lo que pensamos. En esta ritualidad, la moneda pareció tener una funcionalidad diversa que se desprende de los distintos lugares y momentos donde fue depositada en el sepulcro.

\subsection{La moneda en el rito de la inhumación}

Los escasos datos de los que disponemos sobre la exacta ubicación de la moneda en cada enterramiento gadirita de inhumación permiten afirmar que se prefiere depositarla en contacto directo con el cadáver. No obstante, esto no impedía que la moneda pudiera ofrendarse en otros momentos de la escatología, pues la encontramos también en la fosa de enterramiento, en el ajuar, entre el relleno de la tumba y sobre la misma. Parece efectivamente posible afirmar que en el rito de inhumación gadirita la moneda cumplió un papel específico, cuya interpretación se enriquece a medida que conocemos un mayor número de datos concretos en contexto arqueológico.

\subsubsection{La deposición de la moneda en la fosa}

La tipología de las tumbas gadiritas parece conservar una cierta continuidad respecto a los periodos anteriores, pero especialmente se prefería incorporar el numerario en los sepelios de tipología más sencilla. Hemos contabilizado más de doce ejemplos donde la moneda se añadió a sepulturas cimentadas únicamente sobre fosas simples sin ninguna protección. Le siguen muy de cerca las 8 inhumaciones en fosas selladas con lajas o tegulae y a distancia las 2 únicas cistas de piedra que hemos podido identificar (Tab. 1). A falta de un recopilatorio detallado de todas las tumbas exhumadas en las necrópolis de Gadir, no podemos saber si estamos ante una preferencia genérica por enterrar a los difuntos directamente sobre la tierra en estos momentos. Esto pareció ser así, por ejemplo, en la necrópolis tardopúnica y sarda de Bidd' e Cresia (IV-II a.C.) (Van Dommelen 1998: 41), donde primaron los enterramientos en fosa simple y en ánfora y donde las tumbas alla capuccina (con cubierta de lajas) no aparecen hasta el siglo I a.C., relacionándolas sus excavadores con costumbres más bien romanas.
En cronologías anteriores, desde Ugarit a Tiro, Cartago, Mozia, Laurita, Lagos, Sulcis o Palermo (Jiménez Flores 1996: 59), la preferencia por las tumbas más sencillas fue generalizada, primando los enterramientos en fosa o pozo simple y siendo en general muy escasas las inhumaciones en ataúdes de madera o en sarcófagos de piedra antropoides o rectangulares.

Autores como Zamora (2010: 349) ya han llamado la atención sobre el hecho de que enterrar a los difuntos directamente en la fosa y sin ningún tipo de elemento intermedio deja traslucir un sistema de valores y creencias en el que la vuelta a la tierra adquiría un simbolismo especial relacionado con la leyenda de Anath, Baal y Môt, en concreto con la muerte de Baal y su descenso a ultratumba y su triunfo sobre la muerte para alzarse como Señor de la tierra (KTU 1.6: III 2-21).

En dos enterramientos tardopúnicos de $\mathrm{Ga}$ dir la moneda se depositó antes que el cadáver, parece que justo tras completar la excavación de la fosa que lo acogería y formando parte de los preparativos necesarios para sacralizar o ataviar el sepelio. Sabemos que existió la costumbre de preparar con cuidado el lugar de descanso eterno del fallecido, como han sugerido entre otros Aubet (2010: 151), quien constata en Tiro la posible preparación de un lecho de hierbas aromáticas escogidas para contrarrestar la inevitable podredumbre, o bien Benichou-Safar (1982: 250), que propone que la mayoría de los fallecidos cartagineses serían enterrados directamente sobre el suelo de la fosa o bien sobre un fondo de paja. En este mismo sentido preparatorio y de sacralización de la última morada, quizá de forma similar a las deposiciones monetarias fundacionales, podríamos entender la intencionalidad de colocar en esta ocasión la moneda.

Como primer ejemplo gaditano citamos el hallazgo de un numisma indeterminado ubicado directamente sobre la fosa de la inhumación 1 de la Avenida San Severiano5. Ésta fue zanjada directamente en la arena dunar y se ha datado en la primera mitad del I a.C. El segundo caso es el conjunto funerario T29a-d, formado por cuatro fosas simples estrechamente separadas unas

\footnotetext{
${ }^{5}$ Lavado Florido, M. ${ }^{\text {a }}$ L. 2000: Memoria final de la excavación arqueológica realizada en la Avenida San Severiano 21, 23, 25 y 27. Memoria inédita depositada en la Delegación de Cultura de Cádiz: 29-30.
} 
de otras y selladas mediante sillares, del solar ubicado entre la Avenida de Andalucía y la Plaza de Asdrúbal (Perdigones et al. 1987: 39). Sobre la fosa de los enterramientos T29a y T29b se recuperó un cuarto de Gadir de la serie I.2 datado entre 300 y 237 a.C. Si bien desconocemos la cronología de estas tumbas, dado que carecen de ajuar, la aparición de este numisma las sitúa en un momento entre finales del siglo III e inicios del II a.C.

La misma deposición litúrgica inaugural pareció darse en la tumba L-23 de las excavaciones de Johns (1932: 85-89) en la necrópolis de Atlit (Haifa, Israel). En los taludes entre las cámaras b-c, se hallaron dos monedas divisorias argénteas, acuñadas en Sidón y en Tiro, datadas entre finales del V a.C. e inicios del IV a.C. El citado arqueólogo halló además otra moneda de plata sidonia datada en idéntico momento bajo tres enterramientos de la cámara $\mathrm{c}$ de esta misma estructura sepulcral, que afirma que estaba intacta. Ambos ejemplos aseguran que este rito formaría parte de un complejo ritual mortuorio perpetrado desde al menos el siglo IV a.C., asemejado a aquellos fundacionales de los que pudo ser espejo, pues se sacralizaba el lugar de enterramiento mediante la deposición de un numisma.

A juzgar por los casos citados, la ceremonia púnica de enterramiento comportó, desde momentos helenísticos muy tempranos y al parecer al menos hasta finales de época republicana, un primer paso que comprendía tanto la preparación ritual del cadáver mediante su cuidado lavado, embalsamado o no, vestido y maquillado (BenichouSafar 1982: 275; Bartoloni 2005: 117 ss), como la preparación de su último lugar de reposo. La fosa de enterramiento posiblemente pudiera purificarse mediante el depósito de hierbas aromáticas, como se menciona en KTU 6.44 al hablar de la "mirra de la tumba", un aroma utilizado para perfumar el cadáver o bien la fosa propiamente dicha (Zamora 2010: 331, n. 54). En un segundo momento el sepulcro pudiera revestirse con algún tipo de paja y a veces sacralizarse, cual nueva edificación, mediante la moneda. De hecho, este testimonio parece reafirmar la concepción de morada que las culturas orientales concedían desde antiguo a la tumba, que, como recuerda Zamora (2010: 331), desde época ugarítica y el final de la Edad del Bronce, eran entendidas como otra vivienda, distinta, la última, del familiar fenecido.

\subsubsection{La moneda en el cadáver}

La idea que habitualmente llega a la cabeza cuando se piensa en la moneda en la tumba se relaciona con el mito que nos transmiten las fuentes literarias sobre Caronte, el barquero que, por dos óbolos, trasladaba a los difuntos hacia la orilla más allá del río Aqueronte (Díez de Velasco 1988; Cantilena 1995; Ritoré Ponce 2011: 55-74). Para culminar con éxito este viaje, según la tradición del folclore y la literatura, el difunto debía ser enterrado con dos monedas depositadas en la boca. Sin embargo desde hace ya algún tiempo, la arqueología (Dubuis et al. 1999; Arévalo González 2013) ha demostrado una realidad bien diferente.

Sin duda alguna el lugar estrella de la moneda en el ritual funerario fue junto al cadáver (Tab. 1) y gracias a la exhaustiva recopilación de los datos de los que disponemos sobre la exacta disposición de la moneda en relación a las distintas partes del cuerpo del difunto tenemos evidencias parcas pero preciosas para la comprensión del rito funerario y las creencias en el más allá en la necrópolis de Gadir.

En nueve ejemplos la información arqueológica ha conservado el detalle exacto de la posición de la moneda respecto al cadáver $\mathrm{y}$, significativamente, no hemos encontrado numerario en la boca del difunto. En cambio, en la necrópolis cartaginesa de Sidi Yahia (Benichou Safar 1982: 262) o en la púnico maltesa Rabat (Sagona 2002: fig $155, \mathrm{n}^{0} 2$ ) se cuenta algún caso ${ }^{6}$. En Gadir, sólo en una ocasión la moneda aparecía a la altura de la cabeza, posición también constatada en la necrópolis argelina de Djidelli (Astruc 1937: 209, 225-226), pero nada nos autoriza a pensar en una posible relación con el mito de Caronte, pues el numisma no se recuperó en ninguno de los casos en la boca del muerto. Más bien podríamos relacionar esta deposición con la conservación de la ancestral costumbre, ya anunciada en las fuentes ugaríticas, de depositar ofrendas junto a la cabeza del difunto:

\footnotetext{
${ }^{6}$ No obstante, en esas necrópolis tampoco hay razones para relacionar exclusivamente estos hallazgos con el griego mito de Caronte. Igualmente podrían explicarse en relación a la inscripción KAI 11 (Ribichini 2005: 44) que describe las circunstancias del último reposo de un difunto, que, como sus ancestros, quería ser enterrado con una lámina de oro sobre la boca.
} 
"i(Un) vidrio se pondrá sobre mi cabeza! ¡una ofrenda funeraria junto a mi cráneo!" (KTU 1.17: VI 26 ss. en Zamora 2010: 331)

Pese a su lejanía temporal, parece que esta costumbre fosilizada en las fuentes literarias tuvo su claro reflejo en la escatología fenicio-púnica. Así, Bartoloni (2005: 120-121) asegura que en todos los inhumados de época fenicia descubiertos en Monte Sirai se halló un recipiente situado junto al cráneo del difunto, cuestión que parece remembrar el citado poema ugarítico aún en un ambiente tan lejano cronológica y geográficamente.

Este mismo recuerdo advertido en las fuentes parece conservarse de manera muy clara en el gadirita enterramiento 126 de la Avenida de Portugal esquina Avenida Juan Carlos I (Fig. 3A), donde Blanco y Legupín (2010: 579 y 585, no 4-6) reportaron que el cadáver, posicionado en decúbito supino, se acompañó de seis ungüentarios de vidrio dispuestos en torno a su cabeza, en el cuello y en el brazo izquierdo (Fig. 3B). Además, también aparecieron tres unidades de Gadir de la serie VI (Fig. 2D) en el húmero y el radio derechos. La moneda hallada en el radio podría haberse movido de su posible posición original en la mano izquier$\mathrm{da}$, si tenemos en cuenta que los brazos estaban cruzados sobre la pelvis y por lo tanto con la mano en contacto con el codo, lo cual explicaría el lugar donde se documentó. En cualquier caso, se insiste en arreglar el conjunto del ajuar en la parte superior del cuerpo del inhumado (Fig. 3B).

En dos sepelios gadiritas la moneda se colocó sobre el pecho del difunto. Uno es la inhumación 163 del solar de la futura Ciudad de la Justicia, una joven ${ }^{7}$ en cuya mano derecha llevaba un anillo de oro y sobre cuyo tórax se había dispuesto un cuarto de Gadir de la serie VI. Esta costumbre pareció ser relativamente bien conocida entre la población púnica, ya que se recuperaron monedas sobre el pecho, costillas o esternón del difunto al menos en Santa Mónica (Delattre 1893: 1122; Acquaro 2000: 16-17), Lilibeo (Visonà 1994: 131-147), Cartago (Visonà 1994: 135-136, nº 5657 y 140, no 69), Puig des Molins (Mezquida

Sibón Olano, J. F. (ed.) 2007: Memoria final de las excavaciones arqueológicas del Palacio de la Justicia. Cádiz 200405. Memoria inédita depositada en la Delegación de Cultura de Cádiz: 25. Una síntesis de esta intervención fue publicada por Sibón Olano et al. (2010: 148-158).
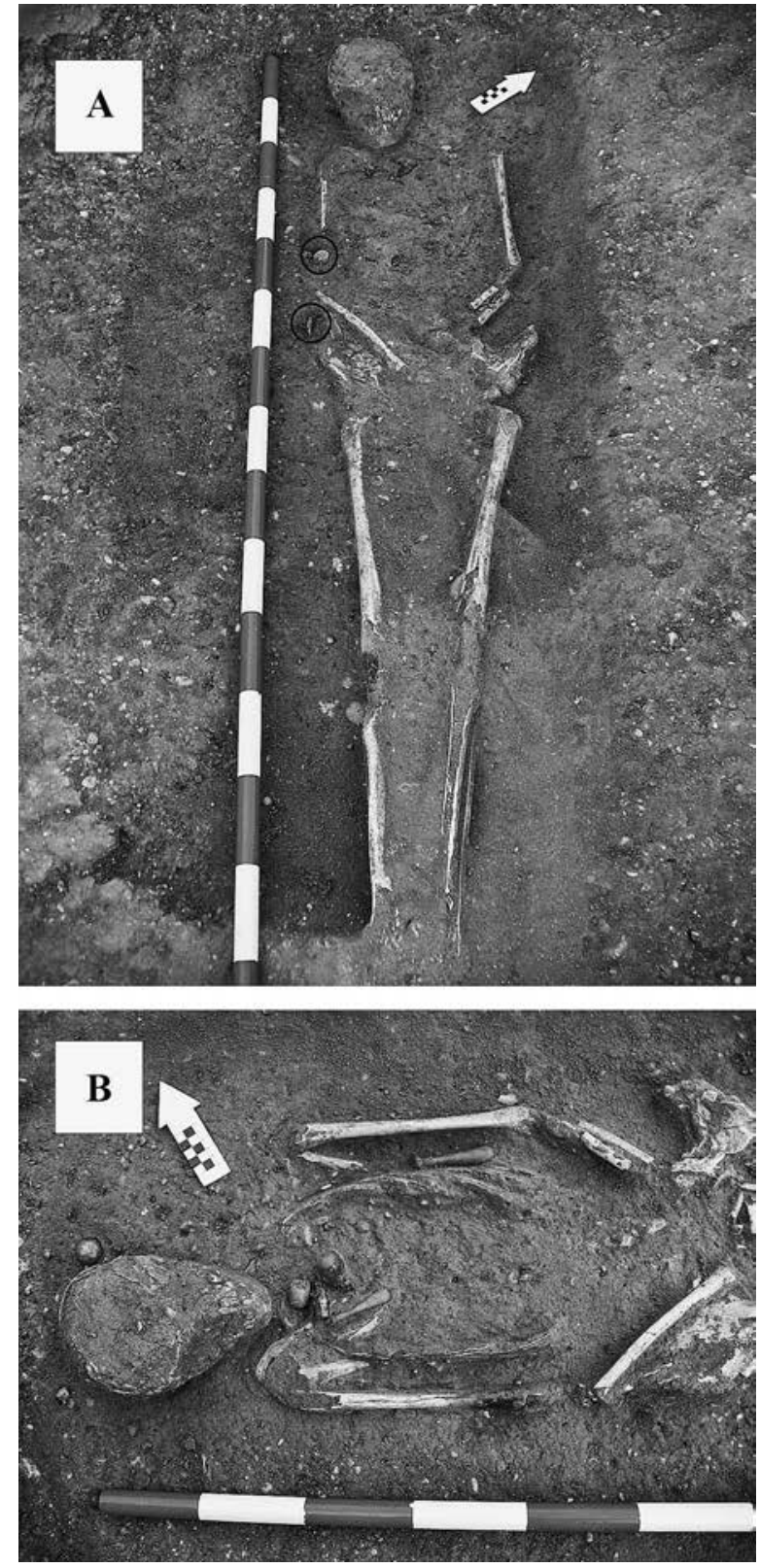

Fig. 3. Detalles del ajuar del cadáver inhumado en la tumba 126 de la Avenida de Portugal esquina Avenida Juan Carlos I (Cádiz, intervención 17): A. Dos monedas en el brazo derecho; B. Ungüentarios dispuestos en torno a la cabeza (fotografías de Francisco Blanco).

2006: 15-24, Mezquida et al. 2007: 24-33), Djidelli (Astruc 1937) y Olbia (Manfredi 1991: 36).

La cuidada colocación de este divisor sobre el pecho de la difunta gadirita desprende un muy posible tratamiento ritual de la moneda como ta-

Trab. Prehist., 74, N. ${ }^{\circ}$ 1, enero-junio 2017, pp. 127-148, ISSN: 0082-5638

doi: $10.3989 /$ tp. 2017.12187 
lismán y objeto profiláctico, el único que aparece entre el ajuar, por otro lado muy escaso. En esta ocasión esa parquedad no se debería a una falta de medios, dado que la joven se atavió con un anillo de oro, sino que, más bien, respondería a una elección cultural, personal o familiar, manifestación de un hecho generalizado en este periodo, caracterizado por un empobrecimiento general de los ajuares funerarios.

El segundo sepelio gadirita es muy diferente. Es el enterramiento 78 de la Plaza Asdrúbal esquina Paseo Marítimo ${ }^{8}$, datado por sus excavadores, nuevamente ante la pobreza del ajuar depositado, entre finales del III a.C. y el I a.C., y siendo la moneda el fósil director del conjunto. Sobre el pecho del cadáver, de sexo desconocido, se halló un divisor de plata de Gadir, serie II.3 (237-206 a.C.), formando parte de un collar de cuentas de cornalina, pasta vítrea y ámbar que se recuperaron distribuidas sobre el tórax y los pies, posiblemente rodadas. Sólo un ungüentario, colocado junto a la cadera derecha, completaba el conjunto. La naturaleza argéntea de la moneda gadirita podría explicar su elección ornamental, aunque no le exime de un posible carácter simbólico y cabalístico. Con todo, llama poderosamente la atención que sea, según los datos que manejamos, la única moneda de plata depositada en época tardopúnica en una inhumación de esta necrópolis. En el resto de los casos se prefirió monetario broncíneo, quizás por su reducido valor, quizás por una específica elección del metal, o más bien por su mayor abundancia, dado que sólo la segunda serie de Gadir, fue acuñada en plata (Fig. 2C). Dicho todo esto, parece que la moneda se incluiría en la tumba como un objeto ornamental y de prestigio más del fallecido, el cual, por su uso continuo y en contacto con el cuerpo, podría haberle concedido alguna otra característica protectora de carácter personal.

Diferente intencionalidad parece desprenderse de la deposición de la moneda en la mano del difunto, cuestión que se observa en Lilibeo (Marsala, Sicilia) (Frey Kupper 1999: 33), Olbia (Cerdeña) (Manfredi 1991: 36) o Monte Luna (Senorbi) (Costa, 1980; Acquaro 2000: 16). En

\footnotetext{
8 Blanco Jiménez, F. J. 1998: Memoria de las excavaciones efectuadas en el solar ubicado en la Plaza de Asdrúbal esquina con el Paseo Marítimo durante 1997/98. Memoria inédita depositada en la Delegación Provincial de Cultura de Cádiz: 56-57.
}

Gadir contamos con dos ejemplos, el primero de la tumba 43 de la calle Tolosa Latour (Perdigones y Baliña 1987: 69), donde un cuarto de la serie I.2 se recuperó muy cerca de las falanges del cadáver. Éste se acompañaría de un recipiente globular y de todo un conjunto de ungüentarios de vidrio, un espejo de cobre y vajilla cerámica (un cuenco común y un vaso de paredes finas), que se situaron entre las piernas, en directo contacto con el cuerpo del cadáver, quizás con el ánimo de que acompañaran, como el último equipaje, al difunto en su viaje al más allá.

El segundo caso es la inhumación 64 del solar del pabellón Fernando Portillo ${ }^{9}$ (Fig. 4A), un adulto indeterminado que se enterraría con una pieza de la serie VI.C.2.1 de Gadir en la mano. Durante la intervención, la moneda se encontró en la caja torácica (Fig. 4B), según sus excava-
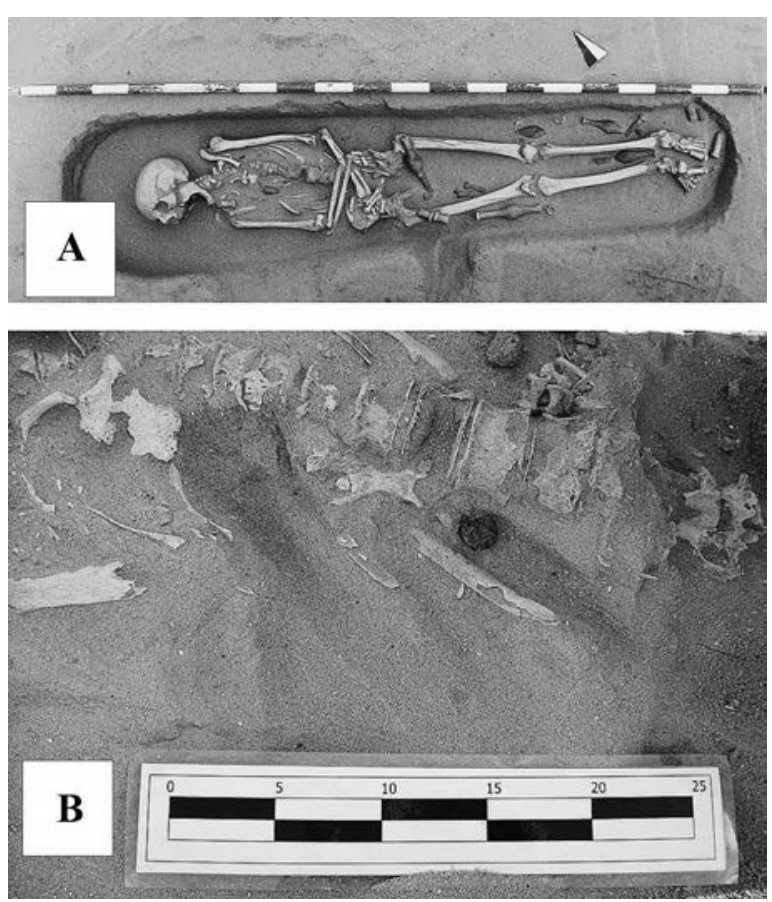

Fig. 4. A. Inhumación 64 del solar del antiguo pabellón Fernando Portillo (Cádiz, intervención 6); B. Detalle de la posición de la moneda (fotografías de $\mathrm{M}^{\mathrm{a}}$ Eugenia García Pantoja).

\footnotetext{
${ }^{9}$ García Pantoja, M. ${ }^{\text {a }}$ E. 2012: Informe de la Intervención Arqueológica Preventiva. Excavación en extensión en el solar del "Nuevo Pabellón Portillo". Informe inédito depositado en la Delegación Provincial de Cultura de Cádiz.
} 
dores posiblemente desplazada desde su posición original en la mano. Además, el conjunto fúnebre contaba con dieciséis ungüentarios fusiformes, un anillo de oro y una cuenta de collar de pasta vítrea, repartidos en torno al cadáver.

Quizás la misma circunstancia sucediera en el ya citado sepelio 126 de la Avenida de Portugal.

La costumbre de enterrar a los difuntos con un objeto entre las manos se constata insistentemente en Cartago donde, según Benichou-Safar (1982: 258-259), los fallecidos sostienen siempre algo entre sus dedos, sea un quemaperfumes, un espejo, un platillo o címbalo, una copa, una lucerna o una ollita. La autora lo interpreta como un símbolo de supervivencia o creencia en la otra vida o bien como un instrumento de oración, circunstancia recordemos que se repite, también, en los famosos sarcófagos antropoides gadiritas. Tal vez esta misma idea se conserve, transformada, en el acto de deposición de la moneda en la mano, sustituyendo a esos otros objetos pero con la misma funcionalidad o implicando aquí un pago o viático necesario para completar el paso a la otra vida.

Curiosamente hallamos numerario casi con la misma frecuencia en la mano que en los pies, colocación constatada hasta en tres enterramientos en Gadir y varios ejemplos en Lilibeo (Frey Kupper 1999: 33) y Olbia (Manfredi 1991: 36). La sepultura 105 del solar gaditano, situado entre la plaza Jesús de la Paz y la Avenida Ana de Viya $^{10}$, acogió a un difunto sobre cuyos pies se colocarían una moneda de bronce indeterminada, un ungüentario fusiforme y un clavo de hierro. En la tumba 34 (Perdigones y Baliña 1987: 67) de la calle Tolosa Latour $n^{\circ} 3$ el numisma fue depositado a los pies del cadáver junto a vajilla de mesa y cocina, una cuenta de collar y una aguja. Por último, en el solar de la futura Ciudad de la Justicia, en los pies de la inhumación $141^{11}$, posiblemente una mujer adulta, se colocaría un cuarto de Gadir de la serie IV.2.1 junto a una cuenta de cornalina y otra de pasta vítrea.

Resulta altamente sugestivo que en los tres casos el conjunto del ajuar se depositara precisamente en los pies del cadáver. Esto parece in-

\footnotetext{
${ }^{10}$ Pineda Reina, P. 2001: Excavación arqueológica de urgencia realizada en la Plaza Jesús de la Paz y Avenida Ana de Viya, $s / n$. Informe inédito depositado en la Delegación Provincial de Cultura de Cádiz.

${ }^{11}$ Véase n. 7: 24.
}

sinuar la creencia en supersticiones ancestrales que concedían a los miembros inferiores un valor especial, por ser la parte del cuerpo más cercana a la tierra y, por ello, la más sensible a la hora de apreciar lugares, eventos y seres sobrenaturales. Así se comprueba insistentemente en el Antiguo Testamento, por ejemplo en el libro del Éxodo (III.5): "No te acerques aquí, quita las sandalias de tus pies, porque el lugar que pisas es suelo sagrado".

Es bien conocido que en los enterramientos de incineración fenicios de época arcaica el ajuar estaba regularmente compuesto por un oinochoe de boca de seta, que contendría ungüentos o perfumes, y otro trilobulado o piriforme, que aparecen habitualmente en enterramientos tanto de la propia costa sirio palestina (Aubet 2006) como cartaginesa (Gras et al. 1989: 177), sarda (Bartoloni 2005) o ibérica (Ramos Sainz 1990; Jiménez Flores 1996). En este sentido es significativo que, como recuerda Bartoloni (2005: 118), estos inexcusables elementos del ajuar se dispusieran siempre donde los pies del difunto. El autor lo atribuye a la necesidad de que estos vasos afloraran, al menos en parte, del túmulo fúnebre para permitir su retirada de la ceremonia de libación sacra o refrigerium. Pero es posible pensar que estos elementos, tan sumamente importantes en la escatología funeraria fenicio-púnica, se colocaran en los pies del difunto en relación con la propia sensibilidad a lo sobrenatural que las creencias orientales atribuían a esta parte del cuerpo. Según Bartoloni (2005: 122) también en las inhumaciones de Monte Sirai se depositarían vasos rituales sobre los pies del difunto que tendrían un uso representativo y no funcional, para nosotras quizá vinculado a la importancia concedida a las extremidades inferiores.

Igualmente llamativa es la relación en dos casos de la moneda descubierta en los pies de los difuntos gadiritas con cuentas de cornalina y pasta vítrea, que nos lleva a preguntarnos si en realidad estamos ante una especie de tobillera o brazalete para adornarlos o salvaguardarlos. De hecho, en las necrópolis fenicias de Atlit (Johns 1937: 140) o de Beirut (Elayi 2010: 167) y siguiendo una costumbre rastreable en épocas más antiguas desde el Cáucaso hasta Egipto (Green 2007: 286), fue muy común enterrar a hombres y mujeres con aros, siempre de bronce, en los tobillos. Estos podían actuar como protectores de esta parte del

Trab. Prehist., 74, N. ${ }^{\circ}$ 1, enero-junio 2017, pp. 127-148, ISSN: 0082-5638

doi: $10.3989 /$ tp. 2017.12187 
cuerpo, especialmente perceptiva y cercana a los malos espíritus de la tierra.

Estas tobilleras, pesados anillos de bronce que una vez colocados eran imposible de retirar sin la ayuda de un instrumento específico, fueron utilizadas también como ring-money, en un sentido de dinero premonetal. A tenor de los datos arqueológicos que ahora presentamos, debemos preguntarnos si quizás esta misma función económica sería sustituida a posteriori por la propia moneda, pues quizá este traspaso de valores económicos del aro de bronce al numisma implicase también, a un nivel muy cotidiano, una transferencia del sentido supersticioso, simbólico y protector de estos objetos. Podríamos estar entonces ante una reinterpretación de estos aros-tobilleras de bronce y que, a tenor de los datos ofrecidos, parecieron componerse en época tardopúnica por una moneda broncínea y una o dos cuentas vítreas o de cornalina, suspendidas por alguna clase de hilo orgánico de cuya existencia no queda rastro y que se colocarían en los pies.

Es más, sabemos que las monedas alejandrinas fueron utilizadas como amuletos colgados en los tobillos inclusive en época tardoantigua, gracias a la cita de Juan Crisóstomo sobre la que ya hemos llamado la atención en otra ocasión (Moreno Pulido 2011): “¿Y qué podría decirse de los que se sirven de hechizos y amuletos y de los que se atan en torno a la cabeza y los pies monedas de bronce de Alejandro Magno?" (Ad Illuminandos Catechesis II, 5). Por tanto, quizá en este caso no estamos frente a un rito estrictamente funerario, sino ante una evidencia de una superstición ancestral donde la moneda actuaba como protectora contra los malos espíritus que podían atacar al individuo por los pies, dado su contacto continuo con la tierra.

La multiplicidad de relaciones entre la posición del numerario, cuando aparece, y el difunto hablan de diversas funciones de la moneda, pero comparten la busca de su contacto directo con el cadáver. La insistencia en dejar moneda sobre determinadas partes del cuerpo del fallecido podría interpretarse como una protección, cual amuleto, dado que portaba la imagen divina o por las cualidades profilácticas concedidas desde antaño al metal. Sin embargo, no podemos despreciar su uso metafórico como otro de los prosaicos elementos (alimentos líquidos y sólidos, lucernas...) necesarios para sobrevivir en la otra vida, ni tampoco olvidar su posible función como viático inexcusable para completar el rito de paso en el que era entendida la muerte.

\subsubsection{Numerario entre el ajuar mortuorio}

Podría decirse, a tenor de los datos ofrecidos en tumbas de todo el Mediterráneo, que las funciones principales del ajuar fenicio púnico fueron adornar al difunto con su joyería particular, protegerlo con amuletos, ataviarlo con objetos personales y acompañarlo con cerámica, con ofrendas líquidas y sólidas para que no sufriera carencias en el más allá o para alimentar a los dioses. Así, por ejemplo, Sader (2005: 81) caracterizaba el ajuar típico de una tumba no violada de Sarepta por cerámica, figuritas en terracota, brazaletes, anillos, argollas de oro para pendientes, cuentas de collar, máscaras, escarabeos y monedas de bronce para facilitar el acceso a la vida del más allá.

A veces la moneda no se colocó sobre el cuerpo, sino que se encuentra en contacto directo con otros materiales (Tab. 1). En la citada tumba 34 de la calle Tolosa Latour (Perdigones y Baliña 1987: 67), se preparó un ajuar compuesto por dos vasos y una ollita de paredes finas, una cuenta de collar de pasta vítrea, una aguja de bronce y un cuarto de Gadir de la serie VI.C.3.1. En esta ocasión todo el conjunto se depositaría a los pies del fallecido, por lo que quizá deberíamos suponer una misma intencionalidad a cada elemento asociado del repertorio. Desgraciadamente, ignoramos si estos vasos y la ollita contenían alimentos líquidos o sólidos, aunque podríamos pensar que así fue o que esa fuera su funcionalidad simbólica, si estuvieron vacíos. En ese caso quizá estemos ante un conjunto, depositado en un mismo momento del ceremonial con el fin de dotar al fallecido de provisiones, de un equipaje completo de enseres necesarios para el último viaje entre los que estaba la moneda.

No obstante, ésta no parece ser la única función posible del numisma en el ajuar. Como vimos en la sepultura 105 de la Plaza Jesús de la Paz ${ }^{12}$ un bronce indeterminado se colocó junto a un ungüentario fusiforme y un clavo de hierro en los pies del difunto. ¿Existió una idea, una ritualidad

\footnotetext{
12 Véase n. 10.
} 
concreta detrás de colocar estos tres dispares elementos juntos? La exigüidad y especificidad de los objetos escogidos para formar parte de este ajuar parecen apuntar a esa misma concreción en su funcionalidad: el ungüentario alejaría malos olores y espíritus, el clavo ${ }^{13}$ sellaría la tumba e impediría levantarse al cadáver y la moneda actuaría como elemento protector o como instrumento para favorecer el éxito en el paso al más allá. Por tanto, el numisma pareció tener en estos momentos una función concreta dentro del ajuar, que apunta a un complejo sistema de creencias en la ultratumba.

\subsubsection{Numismas entre el relleno de la tumba}

La moneda podía ser ofrendada también en el preciso momento del cierre de la tumba, lo que explicaría que la hayamos encontrado entre la tierra que rellenaba la sepultura. Así lo testimonia la estructura funeraria 35 excavada en la confluencia de las calles Santa Cruz de Tenerife y Santa María del Mar ${ }^{14}$, donde una mitad de Gadir de la serie IV.1, datada en el último tercio del siglo III a.C., apareció en el estrato de relleno. También entre la tierra que colmataba el sepulcro de la inhumación 91 del solar de la futura Ciudad de la Justicia ${ }^{15}$ se halló un cuarto gadirita de la serie I, si bien el expolio parcial del cadáver impide asegurar que su posición formara parte del ritual de enterramiento o se tratara, más bien, de una antigua remoción de tierras.

Con todo, nada nos autoriza a considerar que el momento cúspide de la ceremonia de enterramiento, cuando se tapaba definitivamente el cadáver con tierra, estuviera exento de un simbolismo acorde con la solemnidad del evento. Las fuentes

\footnotetext{
13 Los clavos suelen interpretarse como testimonio del uso de parihuelas o ataúdes, lo que no explica la aparición en un significativo número de tumbas de un único clavo, en ocasiones de un tamaño considerable. Su utilidad pudo ser mucho más simbólica y supersticiosa: inmovilizar el cuerpo, teniendo en cuenta el ancestral miedo a los muertos que se constata en las antiguas sociedades orientales (Xella 1987b: 132-133) o bien, ser una alegoría del final de una etapa (Jiménez Díez 2008: 244-248).

${ }_{14}$ Molina Carrión, I. 1997: Intervención arqueológica en un solar de c/ Sta. Cruz de Tenerife $n^{\circ} 1 \mathrm{E} / \mathrm{A}$ c/ Sta. María del Mar. Memoria inédita depositada en la Delegación de Cultura de Cádiz: 44.

${ }^{15}$ Véase n. 7, p. 18.
}

mitológicas recuerdan insistentemente la importancia del mito de Baal y Môt (Xella 2001-2002), donde el dios principal del panteón ugarítico y fenicio era tragado por la tierra al ser derrotado por Môt, para resucitar posteriormente de sus entrañas ayudado por Anath (KTU 1.51 33-35).

Sin duda, la carga ideológica que incluso hoy define el propio acto de enterramiento se apoyaría en un ceremonial que desgraciadamente desconocemos. Sin embargo los datos nos permiten suponer que, además de posibles libaciones, plegarias, sacrificios alimentarios (Niveau de Villedary y Mariñas 2009) y aromáticos, pudieran haberse ofrendado monedas como objeto de fuerte carga simbólica que actuaría en el mismo sentido que el resto de sacrificios, dedicados, como recuerda la literatura (KTU 1.6: I: 16-31), ya no al propio cadáver, sino a las divinidades. En muchos casos esta circunstancia se nos pasa desapercibida, al no prestar suficiente atención a la secuencia estratigráfica en la que aflora cada moneda. De hecho, parece que esta ceremonia no se restringía únicamente a Gadir, pues Johns (1932: 55) ya recogió tres monedas en el relleno de un par de tumbas de la necrópolis de Atlit. En el estrato superior de la tumba L-12, halló una de plata de Aegae (Egas, Acaya, Grecia) acuñada a finales del $\mathrm{V}$ a.C., que supuso en posición secundaria por su proximidad a otro divisor, sidonio, del II-I a.C. El relleno de la cámara de la tumba L-23b ofreció dos numismas sidonios de inicios del IV a.C., pero Johns advertía de una posible alteración de la sepultura durante las obras realizadas en la zona por los cruzados en época medieval.

Es obvio que sólo un escrupuloso tratamiento de los datos arqueológicos en el campo permite $a$ posteriori interpretar correctamente estos detalles $\mathrm{y}$ discernir entre remociones, por expolio u otras circunstancias, de un depósito ritual en el propio relleno, que parece ofrecer una preciosa información litúrgica, hasta ahora pasada totalmente por alto.

\subsubsection{La moneda sobre la tumba}

Sabemos que, en general, las ceremonias escatológicas dedicadas al enterramiento propiamente dicho, finalizaban tras tapar completamente el nicho sepulcral. A veces se localizaba el enterramiento mediante una estela, cipo o betilo, constatándose en

Trab. Prehist., 74, N. ${ }^{\circ}$ 1, enero-junio 2017, pp. 127-148, ISSN: 0082-5638

doi: $10.3989 /$ tp.2017.12187 
Gadir hasta tres tipos según Belén (1992-93). Este acto pareció estar rodeado de simbolismo y protocolo, como muestra la iconografía de un conocido vaso sidonio (Bonnet 1988: pl. 1), pudiendo ofrecerse otros alimentos y libaciones o bien celebrarse los consabidos banquetes funerarios (Niveau de Villedary y Mariñas 2009). Pero tenemos también el dato de que en la tumba 100 del soterramiento de la vía férrea en la Avenida de Portugal ${ }^{16}$, fechada a finales del siglo III a.C., se colocó una mitad de Gadir de la serie I.1 (Fig. 2B) sobre la arena limpia de la playa utilizada para sellar completamente el sepulcro (Arévalo González 2010b: 15-36, 2013: 189). Esta deposición manifiestamente intencionada sobre la tumba tal vez expresaría un final de la ceremonia y del rito, marcado simbólicamente por la colocación de este bronce a modo de cierre y de sacralización del espacio.

\subsection{La moneda en el rito de cremación}

La variabilidad en el rito de deposición de la moneda en las inhumaciones, desafortunadamente, no puede constatarse en las cremaciones tardopúnicas de las necrópolis de Gadir por la poca información arqueológica existente acerca de la localización exacta del numerario en cada intervención. Este dato podría obviarse considerando que la moneda suele encontrarse en el interior de las urnas cinerarias, pero no siempre podemos asegurarlo. Ateniéndonos a los testimonios disponibles, en esta época, en la necrópolis gadirita sólo una moneda se asociaba directamente al ajuar en una urna de incineración. La ausencia de monetario en las cremaciones primarias quizás se deba a que los enterramientos en urnas suelen ser más tardíos.

\subsubsection{Numismas en la urna cineraria}

Los testimonios para afirmar que el monetario se dispondría dentro de las urnas son exiguos y

\footnotetext{
${ }^{16}$ Bernal, D.; Lorenzo, L. y Prados, F. 2002: Informe preliminar y Memoria de la IAU en el Proyecto constructivo para la integración viaria del ferrocarril en el municipio de Cádiz (Zonas $C$ y D). Informe inédito depositado en la Delegación de Cultura de Cádiz.
}

poco concretos. La mayoría provienen de las excavaciones practicadas a inicios del siglo XX por Quintero en las puertas de Cádiz, circunstancia que comporta, comprensiblemente, que la metodología utilizada para recuperar estas monedas no fuera tan detallada como precisamos para nuestra interpretación. Quintero (1917: 6-7) informaba, sin mayor precisión, que halló monedas de Gadir dentro de varias urnas donde también recuperó ungüentarios de vidrio, fragmentos de metal, un peine y una caja de marfil. Las hemos diferenciado como pertenecientes a las series VI.A.1 y VI.B.1 y una unidad de Castulo de la serie IV de García-Bellido (1982).

Durante su campaña en los Baños del Blanco (Quintero 1918: 5-6) exhumaría otro número indeterminado de urnas en cuyo interior se repartían once unidades de la serie VI de Gadir y dos unidades de la serie IV de Castulo. De sus intervenciones en la Playa de los Corrales procedería un conjunto de urnas cinerarias que data entre los siglos III y I a.C., en cuyo interior hallaría un número indeterminado de monedas de Gadir que citaba genéricamente como "de la época cartaginesa y de los primeros tiempos de la dominación romana" (Quintero 1926: 6).

Pero esta exigüidad a la hora de contextualizar el hallazgo de moneda en los informes arqueológicos, por desgracia, no es exclusiva de las antiguas memorias de Quintero. Por ejemplo, las intervenciones en el solar de la futura Ciudad de la Justicia ${ }^{17}$ descubrieron un buen número de cremaciones secundarias. Entre ellas destacamos la número 54: una cista de piedra ostionera y cubierta de arenisca contenía una urna de tradición turdetana y dos unidades de Gadir de la serie VI.B.1.1 (Fig. 2D), que, a falta de mayor detalle, solo podemos suponer que se incluyeron dentro del recipiente.

La imprecisión de los datos nos impide ir más allá de la afirmación de que, en estos momentos, a veces las monedas acompañaban también a los difuntos cremados al introducirse en contacto con las cenizas dentro de las urnas cinerarias. $\mathrm{Su}$ inclusión en el ritual de enterramiento solía sobrevenir tras la quema del cadáver, el cribado de las cenizas y el lavado de los huesos, a veces perfumados y envueltos en sudarios, instante de

\footnotetext{
${ }^{17}$ Véase n. 7, pp. 30-31.
} 
su definitiva colocación en la urna. En ese preciso momento, cuando los restos mortales eran guardados en su postrero recipiente, se podía añadir la moneda con su peculiar significado y simbología.

La costumbre de incluir en la urna funeraria materiales que pertenecieron al difunto, como ornamentos o amuletos personales, se rastrea desde los inicios mismos de la adopción en Tiro del ritual de cremación. Aubet (2010: 149) ha destacado que, entre las más de 320 urnas de cremación que excavó en la necrópolis de Tyr al Bass (Tiro, X-VII a.C.), el 20\% contenía, además de los huesos calcinados del fallecido, un escarabeo o bien objetos personales como pendientes, anillos o diademas, que podían o no haber sufrido la acción del fuego. Esta tradición podría a la postre haberse transformado, incluyendo la posibilidad de colocar una moneda junto a las cenizas.

En efecto, en Cartago la adopción del rito secundario de cremación comportó, según Benichou-Safar (1982: 248) la reducción de los ajuares, que, cuando existían, se limitaban a una o más monedas, siempre cartaginesas y alguna ensortijada. Aunque de forma muy extraordinaria, se depositaban otro tipo de enseres de carácter íntimo y personal u ornamental, incluyendo lucernas, brazaletes, navajas de afeitar, conchas, cristal de roca, espejos, copas, piedras pulidas, improntas de sellos, lacrimatorios, tijeras, tabas o figurillas de marfil.

La pobreza de estos ajuares puede relacionarse, quizá, con una concepción escatológica orientalizante compleja en la que el fuego tenía un papel fundamental. Como muestra la famosa mitología en la que Melqart-Heracles era consumido por el fuego para elevarse posteriormente en toda su divinidad, las llamas eran un medio fundamental para ayudar al difunto en el rito de paso. Purificado a través de ellas, se transformaba del efímero estado mortal a la liberación eterna de la dualidad de las almas Nephesh y Ronah. Sin duda, el testimonio más inmediato de esta transición eran las propias cenizas del difunto, que, en el caso de Gadir, tenían una especial vinculación con el despertar o égersis del dios Melqart, Señor del fuego, pues en su famoso templo se guardaban sus valiosas reliquias (Bonnet 1988).

La moneda de Gadir pudo actuar como un elemento protector y sacralizador de las cenizas, más que como otra provisión para el viaje al más allá, dado que en general sólo una se introdujo en la urna. Un cuerpo, purificado al liberarse de su envoltura carnal por la acción del fuego, podría no necesitar alimentos ni bebidas. Así lo sugiere la ausencia de vajilla de cocina o vasos para libaciones asociadas a estas urnas cinerarias en Cartago y Gadir, como sí ocurría en las inhumaciones. Parece que los objetos personales y amuletos protectores son los incluidos en época tardopúnica dentro de las urnas junto a las cenizas.

Durante los siglos VII-VI a.C., en otras necrópolis, como Laurita o Trayamar (Jiménez Flores 1996: 47; Pellicer 2005: 20-21), Monte Sirai (Bartoloni 2005: 117), Mozia o Tusa (Spanó 2005: 216), los ajuares de incineración habían contenido cooking pots, vasos, copas, platos, páteras, tazas, ánforas, otras formas cerámicas comunes o en barniz rojo, skyphos, ungüentarios, oinochoes de boca de seta y trilobulados, ollas, vasos $a$ chardon, adornos personales, amuletos de pasta vítrea, fayenza o metal, joyas, huevos de avestruz pintados, lucernas o pebeteros, entre otros objetos. En Laurita y Trayamar incluso se halló el servicio cerámico completo en barniz rojo que incluía el oinochoe piriforme para libaciones de agua o vino, de boca de seta para los perfumes, el cuenco para beber y el plato para la comida o el agua para las abluciones. La reducción de los ajuares en época tardopúnica en Gadir podría estar relacionada con una evolución de las creencias y ritos vinculados con la muerte, reflejo cultural, quizás, de la profunda reestructuración que a niveles económicos y políticos estaba sufriendo la ciudad tras la Segunda Guerra Púnica.

\subsubsection{La moneda entre el ajuar cinerario}

Culminaremos nuestro recorrido por el ritual crematorio gadirita con el caso sugestivo y curioso, por único, de la urna ovoide hallada en el enterramiento 51 de la calle García Carrera (Blanco Jiménez 2009: 217-243). Los huesos lavados que pudieron corresponder a una mujer joven fueron introducidos en este recipiente acompañados de un ajuar formado por enseres personales calcinados: un arete de oro, un pequeño píxide argénteo y una cajita de hueso chapada en plata. Además, se incluyeron tres agujas y dos cucharillas de hueso, un espejo, un cartucho y un disco de bronce, un ungüentario fusiforme, un juego de tabas y un

Trab. Prehist., 74, N. ${ }^{\circ}$ 1, enero-junio 2017, pp. 127-148, ISSN: 0082-5638

doi: $10.3989 /$ tp.2017.12187 
conjunto de 38 monedas formado principalmente por unidades y mitades de Gadir de la serie VI, aunque destaca también un denario de la familia Fonteia del 85 a.C. (RRC 353/1b).

En esta ocasión, los objetos personales parecieron arder en la pira, lo cual explicaría que aparecieran quemados y muy deteriorados (Blanco Jiménez 2009: 217-244). Suponemos que el conjunto de monedas quedó protegido del fuego por estar en la cajita de hueso que sería calcinada junto a la joven. El uso de contenedores para depositar monedas destinadas a tumbas, constatado solo una vez en Gadir, cuenta con otros interesantes ejemplos como el del sacerdote de Santa Mónica, enterrado con 24 monedas dentro de una caja dispuesta sobre su pecho y dentro del sarcófago antropoide (Visonà 1994: 135-136, n ${ }^{\circ} 56$ y 57 y 140, $n^{\circ}$ 69; Frey-Kupper 1999: 35), la hucha ebusitana (Costa 2004: 207-241), los vasos de Monte Luna (Acquaro 2000: 16) o los saquitos de tela conteniendo lotes de monedas de Lilibeo (Visoná 1994: 131-147), entre otros.

En el caso gadirita, las monedas no estaban en contacto directo con los restos mortales, pero del hecho de que fueran quemadas junto a otros objetos personales, se desprende que se pretendiera que acompañaran a la difunta en su camino al más allá. Por ende, todo apunta a que se pretendió el contacto entre las cenizas y su ajuar, tanto cuando la moneda se incluyó tras la calcinación de los restos, como cuando se quemó junto a estos. La inusual cantidad de piezas que acompañaban a este enterramiento insinúa en esta ocasión la funcionalidad de la moneda como equipaje, como provisión para sobrevivir una vez había cruzado, esta vez por el fuego, la frontera al más allá.

\section{APROXIMACIÓN A LA PARTICIPACIÓN DE LA MONEDA EN EL RITUAL FUNERARIO GADIRITA}

Los más de 31 casos de monedas en tumbas registrados entre los siglos III-I a.C. (Tab. 1) son muy parcos para el periodo analizado y reflejan su ritualidad marginal en las ceremonias fúnebres de la ciudad de Gadir. Podríamos decir que esta situación contrasta mucho con la que esboza Benichou-Safar (1982: 314 y 318) en su estudio de las tumbas de Cartago. En él asegura que las monedas aparecen en el ámbito funerario cartaginés en el siglo IV a.C. en pocas cantidades para hacerse frecuentes y abundantes en el siglo III a.C., añadiendo incluso que entre los ajuares de inhumación las monedas podían contarse por decenas. Sin embargo la autora no pudo facilitar los detalles que corroborarían esta afirmación como su cuantía e incidencia en relación a las tumbas sin numerario.

Por nuestra parte, a partir de la recopilación estricta de todos los hallazgos monetarios gadiritas en tumbas, concluimos que se trató de un ceremonial seguido por muy pocos y que comienza a partir de que Gadir contara con sus propias acuñaciones. Este tipo de moneda, de forma casi exclusiva, era el que se seleccionaba para la ritualidad funeraria. Esta cuestión parece trascender los límites estrictamente escatológicos y podría vincularse, más bien, con cuestiones de identidad política o religiosa que impregnarían de tal forma la vida cotidiana de los gadiritas que pueden rastrearse, literalmente, hasta la tumba. No obstante, también entrará en juego el factor económico, pues durante este periodo el numerario acuñado por la ciudad circularía monopolísticamente por los ámbitos comerciales, industriales, etc. de la bahía.

En Gadir el uso de la moneda en ámbito funerario se inicia a finales del siglo III a.C., empero, ya se constata su uso en momentos anteriores en Ebusus (Costa 1991: 45-46), Cabezo Lucero (Aranegui et al 1993: 178) y en ambientes contestanos (Verdú Parra 2010: 301-333) y ya parecía común en Cartago (Benichou-Safar 1982) o en ámbitos insulares púnicos (Manfredi 1991; Sader 2005). Es decir, el arranque de este culto en Gadir no se debe al contacto con Roma, sino que es una costumbre ya rastreable en la cultura helenística vinculada a la mismísima aparición de las acuñaciones propias de cada ciudad. Este dato es fundamental pues demuestra claramente que las atribuciones concedidas al numerario fueron mucho más allá de las económicas, entre las que destacan aquellas funciones identitarias y cívicas, que explicarían la elección de numerario propio como viático mortuorio. Además, la moneda en origen fue un objeto de valor ritual y de prestigio utilizado de ordinario en múltiples ambientes sagrados, votivos y cultuales, no solo fúnebres.

Durante la etapa tardopúnica, los enterramientos gadiritas parecen demostrar el mantenimiento

Trab. Prehist., 74, N. ${ }^{\circ}$ 1, enero-junio 2017, pp. 127-148, ISSN: 0082-5638 doi: $10.3989 /$ tp. 2017.12187 
de las formas rituales y las creencias religiosas orientales, lo que sucedería en otros cementerios, como los sardos de Bidd e Cresia (Van Dommelen 1998: 41). Pese a ser caracterizados como "romanos", contienen tumbas datadas entre los siglos III y II a.C. donde los cadáveres son exclusivamente acompañados por objetos de carácter púnico, primando tipologías vinculadas a esta cultura como los enterramientos en ánfora o en fosa simple. En Gadir, la posición de los cadáveres, las tipologías de enterramientos, las vajillas registradas o los ungüentarios helenísticos también parecen asegurar una continuidad respecto a las etapas predecesoras. La ritualidad que se desprende de las múltiples deposiciones monetarias registradas puede ponerse en relación con una religiosidad oriental arcaica, con paralelos en Ugarit, Tiro y la costa sirio-palestina, que trasluce una continuidad de las costumbres fenicias durante este tardío momento. Pero hay que tener en cuenta que la aparición de la moneda coincide con una convulsiva etapa de cambios generalizados en las esferas política y económica, que, lógicamente, tuvo reflejo en los rituales funerarios. El empobrecimiento de los ajuares es uno los cambios más evidentes en los ejemplos estudiados para este trabajo. Esta afirmación no es extensible al conjunto de la necrópolis tardopúnica, ya que aún no contamos con un análisis detallado de todos los registros. Podemos apuntar que, cuando se depositó moneda en las tumbas de los siglos III al I a.C., los ajuares personales y de acompañamiento ofrendados al difunto fueron en general muy escasos. No obstante, no conocemos el registro completo de todos los materiales brindados en siglos anteriores para hacer una comparativa al mismo nivel. Este empobrecimiento pudo suplirse, simbólicamente, mediante la introducción de monetario, que la mayoría de las veces aparece acompañando a uno o dos objetos (Tab. 1), en contraste con la riqueza apuntada para algunos de los conjuntos de enseres ofrendados en época arcaica o púnica (Ramos Sainz 1990; Jiménez Flores 1996).

El fin de la Segunda Guerra Púnica y el sometimiento a Roma instauran un contexto socioeconómico y político traumático que podría haber influido de alguna forma en la mengua de los objetos que se solían llevar a la tumba. La moneda entonces pareció tomar las atribuciones que en periodos anteriores ejercían otros mucho más variados que los que muestra la etapa tardopúnica.
Se observa, por ejemplo, la desaparición de los amuletos egiptizantes que habían caracterizado los enterramientos de los siglos VI-IV a.C. Es más, podemos afirmar que en estos momentos, en la necrópolis de Gadir, no coinciden en un mismo enterramiento amuletos de fayenza o de cualquier otro tipo y moneda.

En la ritualidad funeraria gadirita el numerario tuvo distintas y variadas funcionalidades que dependerían del momento en el que fue depositado en la tumba. Pudo colocarse, no únicamente en relación al cadáver, inhumado o cremado, sino también durante la excavación de la fosa en la que se depositaría el difunto, formando parte del ajuar, ofrendada en el momento de cubrir con tierra el cadáver o, por último, colocada sobre la sepultura tras completar el enterramiento propiamente dicho. Esta relación contextual permite atisbar una multiforme variedad de usos de la deposición de la moneda en la tumba, al tiempo que multiplica las interpretaciones que finalmente pudo tener el numisma en ámbito funerario. Parece clara la implicación de sus posibilidades apotropaicas y profilácticas desde el preciso momento en el que la fosa era excavada hasta su cierre final, por no añadir los rituales posteriores al enterramiento mismo, que implicaban la visita de los familiares de los difuntos o las limpiezas periódicas de la necrópolis, rastreables a partir de las pérdidas y depósitos monetales hallados más allá del ámbito estricto de las propias tumbas (Arévalo González 2009, 2010b).

Desde el inicio de esta ritualidad faltaría una norma rigurosa para colocar la moneda, pues intervino en variados momentos de la liturgia, aunque nunca participaría en dos actos diferentes de la ceremonia fúnebre en un mismo sepelio. Esta diversidad de ubicaciones del numerario es llamativa, pues los rituales mortuorios a menudo son muy estrictos en su liturgia. Como la superstición, en el caso de los temas escatológicos, siempre es mucho más pronunciada y conservadora, reflejaría una intencionalidad diferenciada en cada una de estas deposiciones.

Encontramos en el rito de la inhumación la mayor variedad de situaciones donde la moneda se incorporó al rico ceremonial mortuorio. Jiménez Flores (2002: 123), a la hora de intentar comprender la escatología fenicio-púnica a partir de la arqueología, ya afirmó que los comportamientos funerarios públicos están matizados por los usos y costumbres familiares cuya finalidad última fue 
preservar la memoria y la identidad social y personal del fallecido. Bajo este punto de vista, cobra sentido el uso de la moneda en la multiforme ritualidad funeraria gadirita a la que hemos intentado explicar durante estas páginas. Su uso no respondería a una liturgia cerrada y homogénea, sino más bien a muy profusas y plurales formas de expresión religiosa y cultual. Tales formas, imbricadas entre la tradición y la innovación, reflejan un periodo que se resistía al imparable cambio de escenario acarreado por la fuerza romana y dan lugar a una mezcla de tradiciones, ritualidades y ceremonias con un eco especial en la necrópolis.

\section{AGRADECIMIENTOS}

A M. ${ }^{a}$ Eugenia García Pantoja y Francisco Blanco por las informaciones y fotografías proporcionadas.

\section{BIBLIOGRAFÍA}

Acquaro, E. 2000: "Per una lettura antropologica delle necropoli puniche di Cartagine e di Sardegna". En Atti della Tavola rotonda internazionale La necropoli antica di Karales nell'ambito mediterraneo (Cagliari 1996): 13-17. Cagliari.

Alfaro Asíns, C. 1988: Las monedas de Gadir / Gades. Fundación para el Fomento de los Estudios Numismáticos. Madrid.

Aranegui Gascó, C.; Jodin, A.; Llobregat, E.; Rouillard, P. y Uroz, J. (1993): La nécropole ibérique de Cabezo Lucero (Guardamar del Segura, Alicante). Collection de la Casa de Velázquez $n^{\circ} 41$. Madrid.

Arévalo González, A. 2009: "La moneda en el ámbito funerario y ritual de la necrópolis de Cádiz: los hallazgos en pozos". En A. Arévalo (ed.): XIII Congreso Nacional de Numismática. Moneda y Arqueología (Cádiz 2007). Tomo 1: 197-216. Cádiz.

Arévalo González, A. 2010a: "Monedas para el más allá. Un primer acercamiento desde la necrópolis de Cádiz". En A. M. ${ }^{\text {a }}$ Niveau de Villedary y Mariñas y V. Gómez Fernández (eds.): Las necrópolis de Cádiz. Apuntes de arqueología gaditana en homenaje a J. F. Sibón Olano. Servicio de publicaciones de la Universidad de Cádiz. Cádiz: 507-528.

Arévalo González, A. 2010b: "Interpretación y posibles uso de la moneda en la necrópolis de Gadir". En E. Ferrer Albelda (ed.): Actas del VI Coloquio Internacional del Centro de Estudios Fenicios y Pú- nicos, los púnicos de Iberia, proyectos, revisiones, síntesis. Mainake XXXII (I): 15-36.

Arévalo González, A. 2012: "Continuidad e impronta púnica en la necrópolis de Gades. Evidencias monetales". Cuadernos de Prehistoria y Arqueología de la Universidad Autónoma de Madrid 37-38, 20112012: 525-538.

Arévalo González, A. 2013: “La moneda en los ritos funerarios púnicos, una primera aproximación”. En B. Costa y J. H. Fernández (eds.): La moneda y su papel en las sociedades fenicio-púnicas. XXVII Jornadas de arqueología fenicio-púnica (Eivissa 2012). Trabajos del Museo Arqueológico de Ibiza: 183-222.

Arévalo González, A. y Moreno Pulido, E. 2011: "La imagen proyectada de Gadir a través de sus monedas". En J. C. Domínguez (ed.): Gadir y el Círculo del Estrecho revisados. Propuestas de la arqueología desde un enfoque social. Consejería de Innovación, Ciencia y Empresa de la Junta de Andalucía; Universidad de Cádiz. Cádiz: 321-351.

Astruc, M. 1937: "Nouvelles fouilles à Djidjelli (A1gérie)". Revue Africaine XXX: 209-227.

Aubet, M. ${ }^{\mathrm{a}}$ E. 2006: "Burial symbols and mortuary practices in a Phoenician Tomb". En D. Ridgway; F. R. Serra Ridgway; E. Herring (eds.): Across Frontiers. Etruscan, Greeks, Phoenicians \& Chipriots. Studies in honor of David Ridgway and Francesca Romana Serra Ridgway. Accordia Research Institute, University of London. Londres: 37-47.

Aubet, M. ${ }^{\text {a }}$ E. 2010: "The Phoenician cemetery of Tyre”. Near Eastern Archaeology 73 (2-3): 144-155.

Aubet, M. ${ }^{\text {a }}$ E. 2013: "Cremation and social memory in Iron Age Phoenicia”. En O. Loretz; S. Ribichini; W. G. E. Watson; J. A. Zamora (eds.): Ritual, religion and reason: studies in the ancient world in honour of Paolo Xella. Alter Orient und Altes Testament 404, Ugarit-Verlag. Munich: 77-87.

Bartoloni, P. 2005: "Le necropolis della Sardegna fenicia". En A. González Prats (ed.): El mundo funerario. Actas del III Seminario sobre temas fenicios (Alicante 2004): 117-130. Alicante.

Bartoloni, P. 2015: "Il rituale funebre fenicio e punico: La morte e i morti nelle società euromediterranee". En Atti del Convegno internazionale (Palermo 2013) Acta Diurna 8: 45-58. Palermo.

Belén, M. 1992-1993: "Religiosidad funeraria en la necrópolis prerromana de Cádiz". Tabona. Revista de Prehistoria y Arqueología VIII, II: 351-364.

Benichou-Safar, H. 1982: Les tombes puniques de Carthage. Topographie, inscriptions et rites funéraires. Éditions du CNRS. París.

Blanco Jiménez, F. J. 2009: "Hallazgo inédito de un tesorillo de monedas en el interior de una urna cineraria romana (antiguo cine Brunete-Cádiz)". En A. Arévalo (ed.): XIII Congreso Nacional de Numismática. Moneda y Arqueología (Cádiz 2007) I: 217-244. Cádiz.

Blanco, F. J. y Legupín, I. 2010: “Intervención arqueológica de la primera fase de excavación del solar

Trab. Prehist., 74, N. ${ }^{\circ}$ 1, enero-junio 2017, pp. 127-148, ISSN: 0082-5638 doi: $10.3989 /$ tp.2017.12187 
ubicado en la Avenida de Portugal esquina con la Avenida Juan Carlos I'. Anuario Arqueológico de Andalucía 2006. Junta de Andalucía. Sevilla: 579591. http://www.juntadeandalucia.es/export/drupaljda/Anuario-arqueologico/Anuario-2006/Cadiz.pdf (consulta 16-12-2016).

Bonnet, C. 1988: Melqart. Cultes et mythes de l'Heracles tyrien en Méditerranée. Studia Phoenica VIII, Peeters. Lovaina.

Cantilena, R. 1995: “Un obolo per Caronte?”. En R. Cantilena (ed.): Caronte. Un obolo per l'aldilà. La parola del passato 50: 165-177.

Costa, A. M. 1980: "Santa Teru-Monte Luna (campagne di scavo 1977-79)". Rivista di Studi Fenici VIII-2: 265-271.

Costa, B. 1991: “Las excavaciones arqueológicas en el solar no 38 de la Vía Romana (Can Partit). Nuevos datos para el conocimiento de la necrópolis del Puig des Molins". En I-IV Jornadas de Arqueología fenicio-púnica (Ibiza 1986-89). Trabajos del Museo Arqueológico de Ibiza y Formentera 24, Govern Balear. Ibiza: 29-57.

Costa, B.; Fernández, J.H.; Mezquida, A. 2004: “Ahoros para la otra vida. Una sepultura púnica conteniendo una hucha en la necrópolis del Puig des Molins (Eivissa) y su contexto histórico". En G. Matilla, A. Egea y A. González (eds.): El mundo púnico. Religión, antropología y cultura material: actas del II Congreso Internacional del mundo púnico (Cartagena 2000): 207-242. Murcia.

Delattre, A. L. 1893: "Fouilles archáeologiques dans le flanc sud-ouest de la colline de Saint-Louis en 1892". Bulletin Archaéologique du Comité des Travaux Historiques et Scientifiques: 94-123.

Díez de Velasco, F. 1988: El origen del mito de Caronte. Servicio de publicaciones de la Universidad Complutense. Madrid.

Dubuis, O. F.; Frey-Kupper, S. y Perret, G. (eds.) 1999: Trouvailles monétaires de tombes. Actes du deuxième colloque international du Groupe suisse pour l'étude des trouvailles monétaires (Neuchâtel 1995). Lausana.

Elayi, J. 2010: "An unexpected archaeological treasure: the phoenician quarters in Beirut city center". Near Eastern Archaeology 73 (2-3): 156-168.

Fernández, J. H. 1992: “Excavaciones en la necrópolis del Puig des Molins (Eivissa). Las campañas de D. Carlos Román Ferrer: 1921-1929”. Trabajos del Museo Arqueológico de Ibiza y Formentera 1-3.

Ferrer Albelda, E. 2006: "La bahía de Cádiz en el contexto del mundo púnico: aspectos étnicos y políticos". Spal 15: 267-280.

Ferrer Albelda, E. 2010: "La necrópolis fenicio-púnica de Gadir. Reflexiones a partir de un discurso identi-

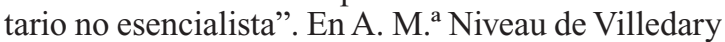
y Mariñas (ed.): Las necrópolis de Cádiz: apuntes de arqueología gaditana en homenaje a J. F. Sibón Olano. Diputación de Cádiz. Cádiz: 69-92.
Frey-Kupper, S. 1999: "La nécropole de Lilybaeum (Marsale) en Sicile: hasard ou exception?". En O. F. Dubuis, S. Frey-Kupper y G. Perret (eds.): Trouvailles monétaires de tombes. Actes du deuxième colloque international du Groupe suisse pour l'étude des trouvailles monétaires. (Neuchâtel 1995): 31-41. Lausanne.

Garbini, G. 1987: "La letteratura dei Fenici". En II Congresso Internazionale di Studi Fenici e Punici (Roma 1987) II: 489-494. Roma.

García-Bellido, M. ${ }^{\text {a }}$ P. 1982: Las monedas de Castulo con escritura indígena. Asociación Numismática Española, CSIC. Barcelona.

Gómez Bellard, C. y Gómez Bellard, F. 1989: "Enterramientos infantiles en la Ibiza fénico-púnica”. Cuadernos de Castellón 14: 211-238.

González Prats, A. (ed.) 2005: El Mundo funerario. Actas del III Seminario sobre temas fenicios (Alicante 2004). Alicante.

Gras, M.; Rouillard, P y Teixidor, J. 1989: El universo fenicio. Biblioteca Mondadori. Madrid.

Green, J. D. M. 2007: "Anklets and the social construction of gender and age in the Late Bronze and Early Iron Age southern Levant". En S. Hamilton, R. Whitehouse y K. Wright (eds.): Archaeology and women. Ancient and modern issues. Left Coast Press, Walnunt Creek. California: 283-311.

Jiménez Díez, A. 2008: Imagenes hibridae. Una aproximación postcolonialista al estudio de las necrópolis de la Bética. Anejos de Archivo Español de Arqueología XLIII, C.S.I.C. Madrid.

Jiménez Flores, A. 1996: Ritual funerario y sociedad en las necrópolis fenicias de época arcaica de la Península Ibérica. Editorial Gráficas Sol. Ecija.

Jiménez Flores, A. 2002: "Notas sobre las creencias funerarias fenicio-púnicas: el culto a los difuntos". En E. Ferrer (ed.): Ex oriente lux: las religiones orientales antiguas en la Península Ibérica. Universidad de Sevilla. Sevilla: 123-140.

Johns, C. N. 1932: "Excavations at Atlit (1930-31)". The Quarterly of the Department of Antiquities in Palestine 2 (2-3): 41-104.

Johns, C. N. 1937: "Excavations at Pilgrim's Castle". The Quarterly of the Department of Antiquities in Palestine 6 (3-4): 121-152.

Manfredi, L. I. 1991: "Le monete delle necropoli". En R. D’Oriano (ed.): Sardò-contributi sull'Olbia punica 6: 33-38.

Mezquida, A. 2006: "Excavaciones en el subsuelo del museo Monográfico del Puig des Molins". Fites: Revista D'arqueologia, Història, Patrimoni, Museologia, Art (Associació d'Amics del Museu Arqueològic d'Eivissa i Formentera) 6: 15-24.

Mezquida, A; Moreno, S.; Sintes, E.; Moltó, F.; Esquembre, M. A. 2007: "Excavaciones en la necrópolis del Puig des Molins. Campaña de 2006". Fites: Revista D'arqueologia, Història, Patrimoni, Museologia, Art (Associació d'Amics del Museu Arqueològic d'Eivissa i Formentera) 7: 24-33.

Trab. Prehist., 74, N. ${ }^{\circ}$ 1, enero-junio 2017, pp. 127-148, ISSN: 0082-5638

doi: $10.3989 /$ tp.2017.12187 
Moreno Pulido, E. 2011: “Hércules en el Hades. Iconografía hercúlea de las monedas procedentes de la necrópolis de Gadir". En M. Campo (ed.): Mites, ofrenes funeràires $i$ monedes. XV Curs d'historia monetària d'Hispània (Barcelona 2011): 103-124. Barcelona.

Niveau de Villedary y Mariñas, A. M. 2009: Ofrendas, banquetes y libaciones. El ritual funerario en la necrópolis púnica de Cádiz. Spal Monografías XI, Universidad de Sevilla. Sevilla.

Niveau de Villedary y Mariñas, A. M. ${ }^{\mathrm{a}}$ y Gómez Fernández, V. (eds.) 2010: Las necrópolis de Cádiz. Apuntes de arqueología gaditana en homenaje a J. F. Sibón Olano. Diputación de Cádiz; Servicio de publicaciones de la Universidad de Cádiz. Cádiz.

Pellicer, M. 2005: "De Laurita a Tavira. Una perspectiva sobre el mundo funerario". En A. González Prats (ed.): El Mundo funerario. Actas del III Seminario sobre temas fenicios. (Guardamar del Segura 2004): 13- 42. Alicante.

Perdigones, L. y Baliña, R. 1987: “Excavaciones de urgencia en un solar de la calle Tolosa Latour (Cádiz) en 1985". Anuario Arqueológico de Andalucía 1985. III Actividades de urgencia, Junta de Andalucía. Sevilla: 63-69.

Perdigones, L.; Muñoz, A. y Marcos, A.1987: “Excavaciones de urgencia en un solar de la Avda. Andalucía esquina Plaza de Asdrúbal (Cádiz)". Anuario Arqueológico de Andalucía 1986, III Actividades de urgencia. Junta de Andalucía. Sevilla: 38-40.

Perdigones, L.; Muñoz, A.; Pisano, G. 1990: La necrópolis fenicio-púnica de Cádiz. Siglos VI-IV a.C. Studia Punica 7.

Prados Martínez, F. 2008: Arquitectura púnica. Los monumentos funerarios. Anejos de Archivo Español de Arqueología XLIV. Madrid.

Quintero Atauri, P. 1917: Excavaciones en Punta de la Vaca y en Puertas de Tierra (ciudad de Cádiz). Memorias de los trabajos realizados en 1916. Junta Superior de Excavaciones y Antigüedades 5. Madrid.

Quintero Atauri, P. 1918: Excavaciones en extramuros en la ciudad de Cádiz en 1917. Junta Superior de Excavaciones y Antigüedades 4. Madrid.

Quintero Atauri, P. 1926: Excavaciones en extramuros en la ciudad de Cádiz en 1924 y 1925. Junta Superior de Excavaciones y Antigüedades 6. Madrid.

Ramos Sainz, M. ${ }^{a}$ L. 1990: Estudio sobre el ritual funerario en la necrópolis fenicias y púnicas de la Península Ibérica. Universidad Autónoma de Madrid. Madrid.

Ribichini, S. 1986: Questiones de Mythologie Phénicienne d'après Philon de Byblos. Studia Phoenicia IV. Religio Phoenicia. Namur.

Ribichini, S. 1987: “Concezioni dell'oltratomba nel mondo fenicio e púnico". En P. Xella (ed.): Archeologia dell'inferno. L'Aldilà nel mondo antico vicino-orientale e classico. Essedue Edizioni. Verona: $147-161$
Ribichini, S. 2005: "Sui riti funerari fenici e punici. Tra Archaeologia e storia delle religioni”. En A. González Prats (ed.): El mundo funerario. Actas del III Seminario sobre temas fenicios (Alicante 2004). Alicante: 43-76.

Ritoré Ponce, J. 2011: “El 'óbolo de Caronte': estado de la cuestión y relectura de fuentes". En M. Campo (ed.): Mites, ofrenes funeràires i monedes. XV Curs d'historia monetària d'Hispània (Barcelona 2011): 55-74. Barcelona.

RRC = Crawford, M. H. 1974: Roman Republican Coinage. Cambridge University Press. Cambridge.

Sader, H. 2005: "Panorama du monde funéraire dans l'Orient phénicien". En A. González Prats (ed.): El Mundo funerario. Actas del III Seminario sobre temas fenicios (Alicante 2004): 77-98. Alicante.

Sáez, A. M.; Luaces, M. y Moreno, E. 2016: "Late Punic or Early Roman? A 2nd century BC deposit from Gadir/Gades (Cadiz Bay, Spain)". Journal of Hellenistic and Material Culture (HEROM) 5(1): 27-77.

Sagona, C. 2002: The archaeology of Punic Malta. Peeters N.V. Herent.

Sibón Olano, J. F. et al. 2010: "Intervención arqueológica de urgencia en el solar de la futura "Ciudad de la Justicia" (Cádiz)". Anuario Arqueológico de Andalucía 2004.2. Cádiz. Consejería de Cultura de la Junta de Andalucía. Sevilla: 148-158.

Van Dommelen, P. 1998: "Punic Persistence. Colonialism and cultural identities in Roman Sardinia". En R. Laurence y J. Berry (eds.): Cultural Identity in the Roman Empire. Routledge. Londres, Nueva York: 25-47.

Vaquerizo Gil, D. 2010a: Necrópolis urbanas de Baetica. Secretariado de Publicaciones de la Universidad de Sevilla. Sevilla.

Vaquerizo Gil, D. 2010b: "Espacio y usos funerarios en el Gades romano: ¿Un lujo sacrificable?”. En A. M. ${ }^{a}$ Niveau de Villedary y Mariñas y V. Gómez Fernández (eds.): Las necrópolis de Cádiz. Apuntes de arqueología gaditana en homenaje a J. F. Sibón Olano. Cádiz: 341-385.

Vaquerizo Gil, D. 2011: "Espacios, usos y hábitos funerarios en la Hispania Romana. Reflexiones y últimas novedades". En J. Andreu Pintado; D. Espinosa Espinosa; S. Pastor (eds.): Mors omnibus instat: aspectos arqueológicos, epigráficos y rituales de la muerte en el Occidente romano. Liceus Historia Antigua. Madrid: 191-232.

Verdú Parra, E. 2010: "Sobre la presencia de monedas púnicas en sepulturas de la necrópolis de l'Albufereta (Alicante)". En E. Ferrer Albelda (ed.): Actas del VI Coloquio Internacional del Centro de Estudios Fenicios y Púnicos, los púnicos de Iberia, proyectos, revisiones, síntesis. Mainake XXXII(1): 301-333.

Visonà, P. 1994: "Carthage. A Numismatic Bibliography". Studi di Egittologia e di Antichità puniche XIII: 124-130. 
Xella, P. (ed.) 1987a: Archeologia dell 'inferno. L'Aldilà nel mondo antico vicino-orientale e classico. Essedue Edizioni. Verona.

Xella, P. 1987b: "Imago mortis nella Siria antica". En P. Xella (ed.): Archeologia dell'inferno. L'Aldilà nel mondo antico vicino-orientale e classico. Essedue Edizioni. Verona: 117-145.

Xella, P. 2001-2002: "Una cuestión de vida o muerte: Baal de Ugarit y los dioses fenicios". Estudios orientales 5-6: 33-45.
Zamora López, J. Á. 2010: "Morir la muerte de todos: creencias y prácticas funerarias en la antigua Siria-Palestina (a través de la información textual y arqueológica de la ciudad de Ugarit)". En J. A. Belmonte y J. Oliva (eds.): Esta Toledo, aquella Babilonia. Convivencia e interacción en las sociedades del Oriente y del Mediterráneo Antiguos. Ediciones de la Universidad de Castilla la Mancha. Cuenca: 315-366. 